UNIVERSIDADE DE SÃO PAULO

FACULDADE DE MEDICINA DE RIBEIRÃO PRETO

DEPARTAMENTO DE NEUROCIÊNCIAS E CIÊNCIAS DO COMPORTAMENTO

\title{
LARISSA APARECIDA BATISTA
}

Manejo de fármacos antiepilépticos após hemisferotomia: implicações em recorrência de crises, aspectos práticos, neuropsicológicos e do desenvolvimento 


\section{LARISSA APARECIDA BATISTA}

\section{Manejo de fármacos antiepilépticos após hemisferotomia: implicações em recorrência de crises, aspectos práticos, neuropsicológicos e do desenvolvimento}

Dissertação apresentada ao Programa de Mestrado Profissional em Neurologia e Neurociências da Faculdade de Medicina de Ribeirão Preto para obtenção do título de Mestre em Ciências.

Área de concentração: Neurologia do Desenvolvimento.

Orientadora: Profa. Dra. Ana Paula Andrade Hamad

Versão Corridida 
Autorizo a reprodução e divulgação total ou parcial deste trabalho, por qualquer meio convencional ou eletrônico, para fins de estudo e pesquisa, desde que citada a fonte.

\section{FICHA CATALOGRÁFICA}

\section{Batista, Larissa Aparecida}

Manejo de fármacos antiepilépticos após hemisferotomia: implicações em recorrência de crises, aspectos práticos, neuropsicológicos e do desenvolvimento. Larissa Aparecida Batista / Orientadora: Ana Paula Andrade Hamad. Ribeirão Preto, 2018.

$63 \mathrm{p} ; 30 \mathrm{~cm}$

Dissertação (Mestrado Profissional) - Universidade de São Paulo, 2018. Área de concentração: Neurologia do Desenvolvimento

1.Hemisferotomia 2. Fármacos antiepilépticos 3. Epilepsia. 
Esta dissertação foi redigida de acordo com as Diretrizes para apresentação de dissertações e teses da USP: documento eletrônico e impresso Parte I (ABNT) 


\section{FOLHA DE APROVAÇÃO}

BATISTA, Larissa Aparecida. Manejo de fármacos antiepilépticos após hemisferotomia: implicações em recorrência de crises, aspectos prático, neuropsicológicos e do desenvolvimento

Dissertação de Mestrado Profissional apresentada à Faculdade de Medicina de Ribeirão Preto/USP para obtenção do título de Mestre em Neurologia. Área de concentração: Neurologia do Desenvolvimento Orientadora: HAMAD, Ana Paula Andrade.

\section{Aprovado em:}

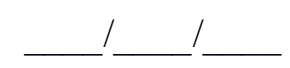

\section{Banca Examinadora}

Prof. Dr.:

Instituição: Assinatura:

Julgamento:

Prof. Dr.:

Instituição: Assinatura:

Julgamento:

Prof. Dr.:

Instituição: Assinatura:

Julgamento: 


\section{DEDICATÓRIA}

À minha família e ao meu namorado, motivos de toda minha busca por evolução pessoal, espiritual e profissional. 


\section{AGRADECIMENTOS}

À minha orientadora Dra. Ana Paula Hamad por sua paciência e generosidade.

À equipe do Centro de Cirurgia de Epilepsia (CIREP) do Hospital das Clínicas de Ribeirão Preto, em especial Dra Úrsula.

As secretárias do centro de cirurgia, técnicas, enfermeiras, assistentes sociais, neuropsicólogas.

Aos funcionários do Hospital das Clínicas de Ribeirão Preto.

Aos colegas neuropediatras pelo apoio e auxilio.

Por fim, aos pacientes que confiam suas vidas em toda esta equipe. 


\section{RESUMO}

BATISTA, Larissa Aparecida. Manejo de fármacos antiepilépticos após hemisferotomia: implicações em recorrência de crises, aspectos práticos, neuropsicológicos e do desenvolvimento. 2018. 63p. Dissertação (Mestrado Profissional) - Faculdade de Medicina de Ribeirão Preto, Universidade de São Paulo, Ribeirão Preto, 2018.

Introdução: a cirurgia de epilepsia é uma opção de tratamento para pacientes com epilepsia refratária. A hemisferotomia pode produzir um controle notável da epilepsia hemisférica clinicamente intratável em crianças. $O$ resultado desejável, após a hemisferotomia, é o controle de crises e a redução ou retirada de fármacos antiepiléticos, visando a melhora cognitiva e do desenvolvimento da criança. Objetivos: verificar a efetividade da hemisferotomia no controle de crises e na retirada ou redução de fármacos antiepilépticos em pacientes classificados como Engel 1, e analisar os desfechos cognitivo e de desenvolvimento após a abordagem cirúrgica e redução de fármacos antiepilépticos. Métodos: revisão de prontuários médicos e banco de dados de pacientes crianças e adolescentes, com idade inferior a 19 anos no momento da cirurgia, submetidos a hemisferotomia para tratamento de epilepsia refratária no Centro de Epilepsia de Ribeirão Preto do Hospital das Clínicas da Faculdade de Medicina de Ribeirão Preto, entre anos de 1995 e 2015. Resultados: foram avaliados 120 prontuários médicos, dos quais foram considerados aptos 82. Amostra sem diferença significativa entre sexos. Para o manejo de fármacos foram considerados 44 pacientes que eram classificados como Engel 1 no segundo ano pós cirúrgico. Para estes pacientes foram avaliadas variáveis como retirada ou redução de fármacos antiepilépticos, bem como o tempo para que esse manejo fosse realizado, além do desfecho cognitivo e de desenvolvimento. Conclusão: A hemisferotomia, quando bemsucedida, permitiu a redução de FAE. A eficácia da hemisferotomia para controle e redução de crises foi verificada nas avaliações pós-operatórias de curto e longo prazos, mas observouse recorrência de crises em longo prazo de seguimento. Não houve consenso no que tange ao tempo mínimo para iniciar a retirada de FAE nos pacientes livre de crises após hemisferotomia. A hemisferotomia e manejo de FAE apresentam impacto positivo sobre o desenvolvimento e função cognitiva, mantendo estáveis, ou melhorando, índices de coeficientes de desenvolvimento e de inteligência.

Palavras-chave: Cirurgia de epilepsia. Hemisferotomia. Fármacos antiepilépticos. 


\begin{abstract}
BATISTA, Larissa Aparecida. Manegement of antiepileptic drugs after hemispherotomy: implications for seizures recurrence, practical, neuropsychological and development aspects. 2018. 63p. Dissertation (Professional Master's degree) - Ribeirão Preto Medical School, University of São Paulo, Ribeirão Preto, 2018.

Introduction: Epilepsy surgery is a treatment option for patients with refractory epilepsy. Hemisferotomy can produce a remarkable control of clinically intractable hemispheric epilepsy in children. The intended outcome, after hemispherotomy, is the seizure control and the reduction or withdrawal of antiepileptic drugs, aiming at the cognitive and developmental improvement of the child. Objectives: To verify the effectiveness of the hemispherotomy in the crisis control and in the withdrawal or reduction of antiepileptic drugs in patients classified as Engel 1, and to analyze the cognitive and developmental outcomes after the surgical approach and reduction of antiepileptic drugs. Methods: review of medical records and database of children and adolescents under 19 years of age at the time of surgery submitted to hemispherotomy for the treatment of refractory epilepsy at the Epilepsy Center of Ribeirão Preto, Hospital das Clínicas, Faculdade de Medicina of Ribeirão Preto between 1995 and 2015. Results: 120 medical records were evaluated, of which 82 were considered suitable. Sample with no significant difference between gender. For the management of drugs, 44 patients were classified as Engel 1 in the second postoperative year. For these patients, variables such as withdrawal or reduction of antiepileptic drugs were evaluated, as well as the time for this management to be performed, in addition to the cognitive and developmental outcome. Conclusion: The successful hemispherotomy allowed the reduction of AEDs. The efficacy of the hemispherotomy for control and reduction of seizures was verified in the shortterm and long-term postoperative evaluations, but there was a recurrence of long-term followup seizures. There was no consensus regarding the minimum time to initiate withdrawal of AED in patients free of seizures after hemispherotomy. Hemispherotomy and management of AEDs have a positive impact on development and cognitive function, maintaining stable, or improving, coefficients of development and intelligence indices.
\end{abstract}

Keywords: Epilepsy surgery. Hemispherotomy. Antiepileptic drugs. 


\section{LISTA DE TABELAS}

Tabela 1 - Distribuição da procedência dos pacientes da pesquisa, CIREP - HCFMRP, 2018 ......

Tabela 2 - Distribuição da idade dos pacientes no momento da realização da cirurgia, CIREP - HCFMRP, 2018.

Tabela 3 - Distribuição da duração da epilepsia, CIREP - HCFMRP, 2018

Tabela 4 - Distribuição etiologia categorizadas por meio de ressonância magnética, CIREP-HCFMRP, 2018

Tabela 5 - Distribuição da frequência de crises no pré-operatório, CIREP - HCFMRP, 2018

Tabela 6 - Número de fármacos antiepilépticos utilizados pelos pacientes no momento pré-operatório, CIREP - HCFMRP, 2018 ................................................. 38

Tabela 7 - Engel ao longo do seguimento pós-operatório, CIREP - HCFMRP, 2018 ....... 38

Tabela 8 - Distribuição do número de fármacos antiepilépticos utilizadas no período pós-operatório, CIREP-HCFMRP, 2018 …............................................ 38

Tabela 9 - Distribuição do percentual de retirada dos fármacos antiepilépticos no pósoperatório, CIREP-HCFMRP, 2018

Tabela 10 - Relação entre percentual de retirada dos fármacos antiepilépticos no último retorno e resultado comparativo da avalição neuropsicológica pré e pósoperatório. 


\section{LISTA DE QUADROS}

Quadro 1 - Exemplo do esquema de FAE utilizado por um paciente (paciente 32) para ilustrar o calculo do Índice relativo de dose de FAEs, CIREP - HCFMRP........ 31 


\section{LISTA DE GRÁFICOS}

Gráfico 1 - Classificação pré-operatória do coeficiente de inteligência e de desenvolvimento após avaliação neuropsicológica ou avaliação de comportamento adaptativo 40

Gráfico 2 - Classificação pós-operatória dos coeficientes de inteligência e de desenvolvimento após avaliação neuropsicológica ou avaliação de comportamento adaptativo. .41

Gráfico 3 - Comparação entre os resultados das avaliações neuropsicológicas pré e pósoperatória

Gráfico 4 - Percentual retirada FAEs (caso 13), CIREP - HCFMRP, 2018........................ 43

Gráfico 5 - Percentual retirada FAEs (caso 14), CIREP - HCFMRP, 2018........................ 43

Gráfico 6 - Percentual retirada FAEs (caso 19), CIREP - HCFMRP, 2018........................ 44

Gráfico 7 - Percentual retirada FAEs (caso 31), CIREP - HCFMRP, 2018......................... 44 


\section{LISTA DE ABREVIATURAS E SIGLAS}

CIREP

CNRAC

DC

DRS

EEG

EME

EPC

FAE

HCFMRP

HME

ILAE

MDC

PO

POI

$\mathrm{RM}$

SPECT

SUS

TFD

QV

V-EEG

WISC
Centro de cirurgia de epilepsia sis

Central Nacional de Regulação de Alta Complexidade

Depois de Cristo

Departamentos Regionais de Saúde

Eletroencefalograma

Estado de Mal Epiléptico

Epilepsia parcial contínua

Fármaco antiepiléptico

Hospital das Clínicas da Faculdade de Medicina de Ribeirão Preto

is

Hemimegalencefalia

Liga Internacional Contra a Epilepsia

Malformação do desenvolvimento cortical

Pós-operatório

Pós-Operatório imediato

Ressonância magnética

Tomografia Computadorizada por emissão de fóton único

Sistema Único de Saúde

Tratamento Fora de Domicílio

Qualidade de vida

Vídeo-eletroencefalograma

Escala de Inteligência Wechsler para Crianças 


\section{SUMÁRIO}

1. INTRODUÇÃO .................................................................................................. 14

1.1. Epilepsia: etiologia do termo, definição, epidemiologia, refratariedade, tratamentos gerais em adultos e crianças ...................................................... 14

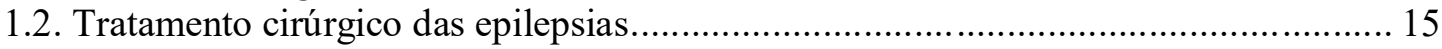

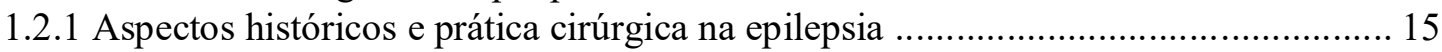

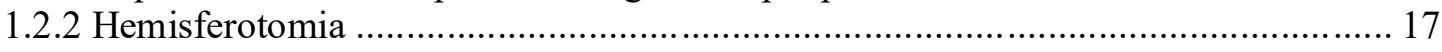

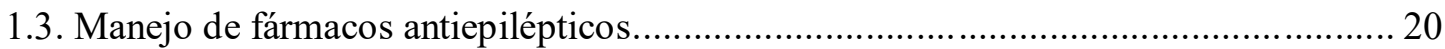

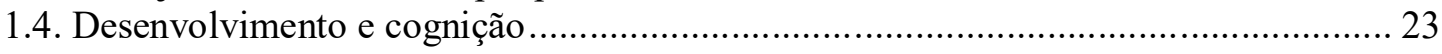

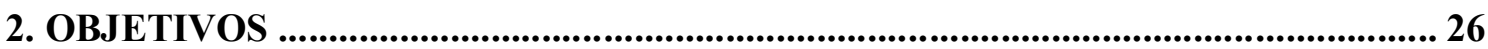

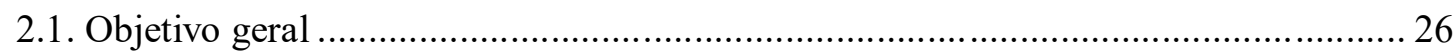

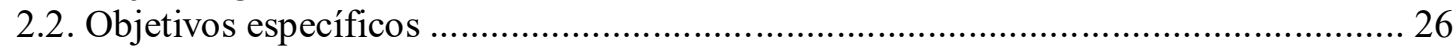

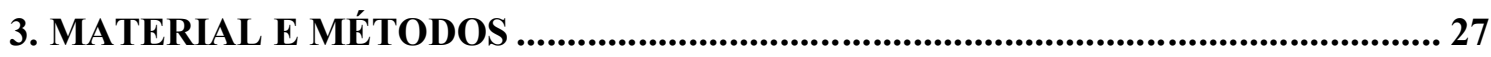

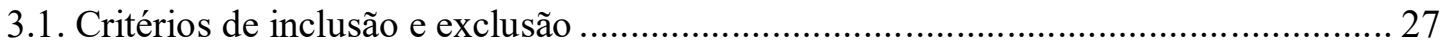

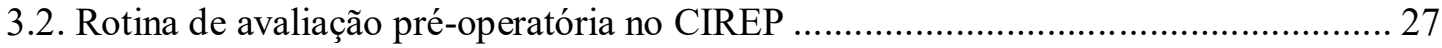

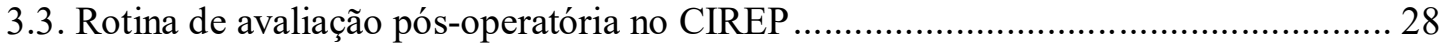

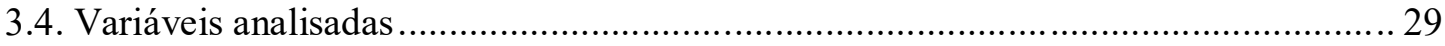

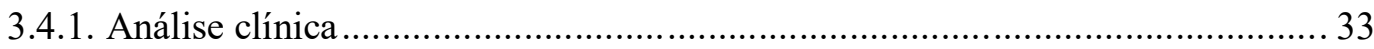

3.4.1.1. Desfechos para controle de crises ............................................... 33

3.4.1.2. Desfechos neuropsicológicos - desenvolvimento e dados cognitivos... 33

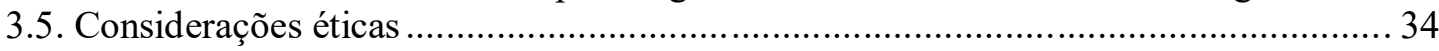

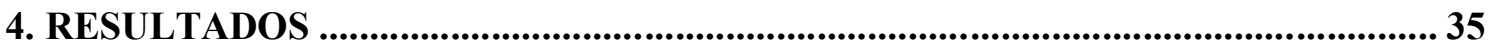

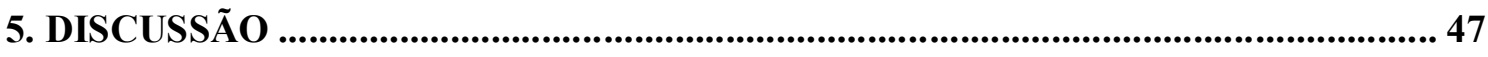

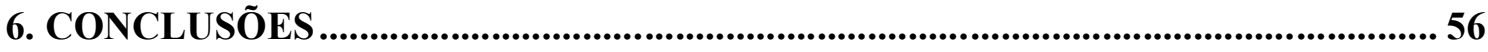

REFERÊNCIAS BIBLIOGRÁFICAS ............................................................. 57

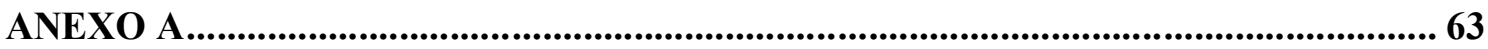




\section{INTRODUÇÃO}

\subsection{Epilepsia: etiologia do termo, definição, epidemiologia, refratariedade, tratamentos gerais em adultos e crianças}

O termo epilepsia é derivado da palavra grega epilambanein, que significa ataque ou crise. Pensava-se que indivíduos epilépticos eram visitados por demônios ou deuses. No entanto, em 400 A.C., Hipócrates sugeriu que a epilepsia era uma desordem cerebral (NATIONAL INSTITUTE OF NEUROLOGICAL DISORDERS AND STROKE, 2010).

Epilepsia é um distúrbio cerebral complexo envolvendo descargas elétricas cerebrais anormais, excessivas e sincrônicas dos neurônios (RHODES et al., 2005). A incidência anual de epilepsia tem sido estimada em 50 para 100.000 e a prevalência afeta cerca de $0,5 \%$ a $1 \%$ da população mundial, acometendo mais de 50 milhões de pessoas (EPILEPSY FOUNDATION, 2010). No Brasil, um estudo populacional estimou a prevalência urbana de epilepsia de 1,86\% (BORGES et al., 2004).

$\mathrm{Na}$ faixa etária pediátrica, a epilepsia é uma condição comum. A cada ano, 200.000 novos casos de epilepsia são diagnosticados e 45.000 crianças menores de 15 anos são afetadas, sendo o sexo masculino mais acometido que o sexo feminino (EPILEPSY FOUNDATION, 2010).

Quando o neurologista faz o diagnóstico de epilepsia, o próximo passo é selecionar a melhor forma de tratamento. O início do tratamento é usualmente realizado com fármacos antiepilépticos (FAEs). Caso os fármacos não sejam eficazes para o controle de crises, terapias complementares são utilizadas, dentre elas a cirurgia, estimulação de nervo vago, dieta especial ou outras terapias complementares. A meta do tratamento é prevenir novas crises, evitar efeitos adversos e permitir ao paciente que mantenha suas atividades de vida diárias (LOWENSTEIN et al., 2008).

Crises epilépticas mal controladas podem acarretar danos físicos, cognitivos, psicológicos e sociais para os pacientes; desta forma, a indicação cirúrgica criteriosa, ao possibilitar eficiente controle de crises, pode contribuir positivamente para a qualidade de vida dos pacientes com epilepsia refratária (AMARAL et.al., 2014).

Cerca de 25 - $30 \%$ dos pacientes apresentam crises epilépticas refratárias à terapia medicamentosa (ENGEL et al., 2003; WIESER et al., 2003), frequentemente associadas a alterações no desenvolvimento, distúrbios cognitivos, transtornos de aprendizagem e mudança 
comportamental, com impacto sobre a qualidade de vida (QV). Por vezes, essas epilepsias são passíveis de tratamento cirúrgico (HAUSER et al., 1996; ANNERGERS et al., 1979).

A realização da cirurgia para o controle de crises refratárias, associada a possibilidade de redução ou retirada de FAEs em pacientes pós-cirúrgicos livres de crises, acarretará benefícios no que tange à diminuição de morbidades e exploração do potencial de reorganização do cérebro em desenvolvimento.

\subsection{Tratamento cirúrgico das epilepsias}

\subsubsection{Aspectos históricos e prática cirúrgica na epilepsia}

Segundo Feindel, em sua revisão sobre a história da epilepsia publicada em 2009, o ano de 1909 se destaca como um marco nos anais da história da epilepsia e como um ano de esperança para os milhões de pacientes afligidos por crises epilépticas, visto que neste ano aconteceu, em Budapeste, a reunião inaugural da Liga Internacional Contra a Epilepsia (ILAE), contando com presença de neurologistas e neurocirurgiões emergentes. Entretanto, a experiência com cirurgia para tratamento de epilepsia já era iniciada no século anterior. A observação de Paul Broca (1824-1880) de que as lesões cerebrais focais produziam déficits de fala e a demonstração de Gustav Fritsch e Eduard Hitzig (1838-1907) de que sítios seletivos do córtex cerebral podiam ser excitados pela estimulação elétrica para produzir respostas motoras específicas, levou Hughlings Jackson a considerar a epilepsia focal como uma manifestação irritativa cortical. Foi então sugerido tratamento por remoção do foco irritativo e Victor Horsley foi o neurocirurgião responsável por realizar uma craniotomia na tentativa de curar a epilepsia. O paciente James B., um escocês de 22 anos, tinha sido atropelado em Edimburgo enquanto criança, quando sofreu uma fratura de crânio com dano cerebral local que, aos 15 anos, levou a episódios de crises epilépticas e status epilepticus com risco de vida. As crises eram motoras focais. Horsley apresentou este e outros dois casos semelhantes com crises focais operados à British Medical Association (HORSLEY et al., 1886). Os resultados de Horsley, para cirurgia de epilepsia, foram inicialmente favoráveis. Avanços adicionais no tratamento cirúrgico da epilepsia focal ocorreram com o desenvolvimento de agentes anestésicos locais, com melhor assepsia e hemostasia (FEINDEL et al., 2009).

A evolução científica e a ideia, cada vez mais concreta, de se obter sucesso no controle das crises epilépticas por meio cirúrgico se espalharam com rapidez por todo o mundo no fim do século XIX e início do século XX. Até a década de 1920, as cirurgias eram realizadas 
somente para epilepsia crônica e localizada, sendo que os conhecimentos da época permitiam programar a região a ser operada somente com base na semiologia e observação clínica pormenorizada das crises apresentadas pelos pacientes. Durante a cirurgia, identificavam visualmente alterações anatômicas corticais a serem ressecadas. Com a invenção e aplicação do eletroencefalograma (EEG), o reconhecimento das áreas epileptogênicas auxiliou no diagnóstico e na determinação da área cerebral a ser ressecada previamente ao ato cirúrgico (PASSOS, 2016).

Bailey e Gibbs, em 1951, relataram séries de pacientes com epilepsia do lobo temporal submetidos à ressecção cirúrgica desta porção. No Brasil, o início do tratamento cirúrgico da epilepsia remonta aos anos de 1950 com a publicação de Paulo Niemeyer sobre amígdalohipocampectomia por um acesso transventricular para o tratamento da epilepsia do lobo temporal, em 1957-58, com resultados expressivos no controle das crises. O primeiro programa voltado para a cirurgia da epilepsia no Brasil foi estabelecido na década de 1970, na Universidade de São Paulo, pelo neurocirurgião Raul Marino Júnior (PASSOS, 2016).

Costa e Portela, em 2006, publicaram um artigo de revisão sobre cirurgia de epilepsia na infância relatando que a cirurgia da epilepsia tem como objetivo o controle das crises e a melhora da qualidade de vida do paciente sem determinar sequelas inaceitáveis. Uma vez constatada a refratariedade das crises ao tratamento medicamentoso, o paciente deverá ser investigado para a correta localização da área responsável pelas crises, utilizando-se o vídeoEEG para registro das crises, a avaliação neuropsicológica e os exames funcionais e anatômicos de neuroimagem. Em relação ao momento da cirurgia, os pacientes mais jovens apresentam melhores resultados quanto aos aspectos psicossociais; a maior incidência de tumores ocultos nas epilepsias parciais refratárias na criança favorece uma intervenção precoce; a longa espera entre o início da epilepsia e a cirurgia pode predispor a um controle mais pobre das crises e a neuroplasticidade, que é um importante aliado nas crianças, pode reduzir o risco de déficit pós-operatório (PO). O maior objetivo da cirurgia da epilepsia é o controle absoluto das crises. É importante também considerar o seguimento global do paciente, incluindo a satisfação dos pais, a melhora no desenvolvimento neuropsicomotor e social, as atividades da vida diárias, as modificações comportamentais e o rendimento escolar. Nas séries pediátricas, $60-100 \%$ dos pacientes tem uma boa evolução pós-operatória. Os pacientes com epilepsia temporal têm uma maior taxa de controle de crises quando comparados com o grupo extratemporal. Conclui que a cirurgia da epilepsia em crianças é uma opção real para casos selecionados e tende a se expandir, sendo importante reconhecer as formas de epilepsia que tem um curso catastrófico, evitando tentativas demoradas de controle com FAEs que não 
mudarão a evolução da doença e que, retardando o tratamento cirúrgico, podem piorar o prognóstico. A terapêutica cirúrgica só deve ser indicada se houver uma boa oportunidade de melhorar a qualidade de vida do paciente (COSTA; PORTELA, 2006).

De acordo com a idade do paciente, a etiologia da epilepsia, a topografia e eloquência da área suspeita para a epileptogênese, varia a indicação da abordagem cirúrgica. Para o tratamento de epilepsias decorrentes de doenças hemisféricas na infância, a hemisferotomia é o procedimento de escolha a ser adotado como tratamento curativo ( OBEID et al., 2009a) .

\subsubsection{Hemisferotomia}

Hemisferotomia é uma intervenção cirúrgica eficaz. A abordagem cirúrgica hemisférica, no caso a hemisferectomia, tem sido usada para lesões hemisféricas desde 1928, descrita independentemente por Walter Dandy's e L'Hermitte como um tratamento radical para glioma maligno de um hemisfério, mas com falha na sobrevivência e na melhora da qualidade de vida, quando comparada com outras técnicas mais conservadoras (RASMUSSEN, 1983).

$\mathrm{O}$ procedimento foi abandonado por anos devido à morbidade e à mortalidade, mas foi repopularizado em 1950 por Krynauw, que usou no tratamento de hemiplegia infantil (KRYNAUW, 1950). As técnicas da hemisferectomia sofreram muitas mudanças ao longo dos anos, com Rasmussen desenvolvendo a hemisferectomia funcional, em 1974, que, por sua vez, sofreu novas modificações, com variações de técnicas de hemisferotomia, com taxas de mortalidade muito baixas (KOUBEISSI et al., 2009). A hemisferectomia/hemisferotomia tem sido usada para tratamento de epilepsia em associação com hemiplegia há 50 anos.

Avanços significativos foram feitos em cirurgia para epilepsia intratável ao longo do último século. Definir a zona epileptogênica de forma não invasiva utilizando novas técnicas permitiu prever a melhor cirurgia a ser realizada, bem como deixar os pacientes livres de crises. A introdução de novas técnicas de neuroimagem contribuiu para investigação de crianças com epilepsia. A hemisferectomia, outrora associada a uma morbidade significativa, também evoluiu para um procedimento seguro e eficaz diante da epilepsia refratária. O estudo rápido e a investigação adequada permitiram definir quem eram as crianças candidatas à hemisferectomia precocemente e aquelas que poderiam ir à cirurgia com a expectativa de controle de crises a longo prazo (BEIER et al., 2013).

A cirurgia de hemisferectomia progrediu para um conjunto de procedimentos refinados praticados rotineiramente nos principais centros de epilepsia ao redor do mundo. 
Embora haja uma variedade de versões aceitáveis da cirurgia de hemisferectomia com antecedentes comprovados, há uma tendência clara para o abandono de hemisferectomias anatômicas e adoção de técnicas de hemisferotomia que envolvem mais desconexão e menos ressecção, com o objetivo de proporcionar controle de crise, reduzindo as complicações associadas às técnicas. A hemisferectomia por desconexão, ou hemisferotomia, consiste em desconectar o hemisfério e deixar o tecido cerebral vascularizado no compartimento hemisférico (VILLEMURE, 2003). Com a seleção adequada do paciente, os resultados geralmente são excelentes no que diz respeito ao controle de crises e complicações graves. A maioria dos pacientes seguidos ambulatorialmente no PO apresenta preservação da função cognitiva (LEW, 2014).

A hemisferotomia, para o controle de crises farmacologicamente refratárias, é indicada quando há uma patologia hemisférica difusa que está associada a uma síndrome hemisférica, isto é, hemiplegia e/ou hemianopsia. Em certas condições progressivas, como Síndrome de Sturge-Weber e encefalite crônica de Rasmussen, a cirurgia pode ser considerada antes do desenvolvimento de déficits máximos. (VILLEMURE, 2003).

Lew, em 2014, publicou uma revisão bibliográfica sobre a história e evolução da hemisferectomia e demonstrou as condições patológicas para as quais a hemisferectomia seria uma indicação adequada, sendo constatado que, em 1118 estudos avaliados, 402(36\%) dos casos apresentavam malformação do desenvolvimento cortical (MDC), 376(34\%) apresentavam isquemia, 213(19\%) encefalite de Rasmussen e 127 outras causas (11\%) (LEW, 2014).

A importância de determinar as doenças consiste no fato de que certas condições apresentam crises mais refratárias, com pior controle de crises no PO. $\mathrm{Na}$ displasia hemisférica difusa, por exemplo, as crises são muito refratárias, levantando a questão da indicação de hemisferectomia; clinicamente, esta condição também pode ser acompanhada de graus de hemiparesia e hemianopsia, associados ao retardo psicomotor. A hemisferectomia foi considerada para o tratamento de crises secundárias à displasia hemisférica difusa; alguns relatos indicam um desfecho menos favorável quando a hemisferectomia é realizada para displasia, em comparação com outras indicações, como a hemiplegia infantil, a encefalite de Rasmussen e a doença de Sturge-Weber. A displasia hemisférica consiste em uma malformação, sem ou com ampliação volumétrica de um hemisfério. No primeiro caso, classificou-se como transtorno predominantemente migratório difuso e no segundo como hemimegalencefalia (HME). Essas entidades são encontradas isoladas ou em associação com lesões cutâneas, como parte de uma síndrome neurocutânea (VILLEMURE, 2003). 
HME é uma malformação congênita hamartomatosa rara do cérebro. $\mathrm{O}$ padrão de epilepsia na HME pode ser crises parciais ou pode apresentar-se como espasmos como encefalopatia epiléptica (KULKARNI et al., 2015), atividade epiléptica que por si contribui para comprometimentos cognitivo e comportamental grave, além daqueles que seriam esperados pela patologia isolada (BERG et al., 2010). A epilepsia associada à HME é geralmente resistente aos FAEs e requer intervenção cirúrgica. A desconexão hemisférica tem sido relatada como sendo eficiente no controle destas crises e previne novas lesões cognitivas e atraso no desenvolvimento. Assim, apesar dos riscos do procedimento, a cirurgia precoce deve ser preferida em lactentes com HME (KULKARNI et al., 2015).

A hemisferotomia em bebês muito jovens é viável, mas deve ser realizada em centros com vasta experiência em neurocirurgia e epilepsia pediátricas. Uma equipe multidisciplinar que inclui neurocirurgiões pediátricos, anestesiologistas, especialistas em cuidados intensivos e neurologistas é necessária para fornecer um ambiente seguro para este procedimento. As potenciais complicações e desafios cirúrgicos devem ser antecipados quando a natureza muito grave da doença leva os profissionais à tomada de decisão pela hemisferectomia funcional no cérebro muito imaturo e vulnerável (DORFER et al., 2015).

Para alguns casos selecionados com atividade epiléptica hemisférica difusa, isto é, após o dano hipóxico perinatal, a encefalite de Rasmussen, a doença de Sturge-Weber, a malformação congênita, como a HME, a hemisferotomia representa um tratamento cirúrgico efetivo com uma taxa média de sucesso (livre de crise ou melhora importante) de $80 \%$ (VADERA et al., 2012; LIMBRICK et al., 2009).

A hemisferotomia pode produzir um controle notável da epilepsia hemisférica clinicamente intratável em crianças. Contudo, alguns pacientes continuam a sofrer crises após a cirurgia. A causa frequente da falha cirúrgica é a desconexão incompleta. Atenção cuidadosa à técnica cirúrgica pode minimizar as falhas cirúrgicas e a necessidade de cirurgia adicional (BAUMGARTNER et al., 2017).

Os resultados para controle de crises são positivos, homogêneos e estáveis ao longo da história (IGNELZI; KRYNAUW et al., 1950; LETTORI et al., 2008; RASMUSSEN, 1983) . O índice de remissão de crises varia de 52 a 86\%, ampliando-se para 78 a $91 \%$ quando se considera a melhora significativa das crises, o que, em se tratando de epilepsias graves, é um resultado altamente satisfatório. Os pacientes foram acompanhados no PO em curto e em longo prazos por pelo menos quatro a sete anos, com eventuais seguimentos de até 27,3 anos (BASHEER et al., 2007; BULTEAU et al., 2008; CARRENO et al., 2001; CATS et al., 2007; DEVLIN et al., 2003; DI ROCCO et al., 2006; DUCHOWNY et al., 1998; FLACK et al., 
2008; GONZALEZ-MARTINEZ et al., 2005; JONAS et al., 2004; KOSSOFF et al., 2003; LETTORI et al., 2008; O'BRIEN et al., 2006; PEACOCK et al., 1996; TERRABUSTAMANTE et al., 2007; TERRA-BUSTAMANTE et al., 2009; VINING et al., 1997).

\subsection{Manejo de fármacos antiepilépticos}

Aproximadamente $50 \%$ das crianças com epilepsia de início na infância, eventualmente, tem uma remissão completa e não requerem tratamentos muitos longos com FAEs (SILLANPAA, 1998; ARTS et al., 2004; SHINNAR, 2000). Normalmente, estas crianças apresentam poucas crises, recebem FAEs diariamente durante vários anos, tornam-se livres de crises e interrompem o tratamento com sucesso. O período sem crise antes de descontinuar fármacos não é bem estabelecido, mas parece ser de 1 a 2 anos (BERG et al.,1994). O fármaco pode ser reduzido durante um período de 6 semanas; não havendo vantagem em reduzir em período mais longo (TENNISON et al.,1994). Infelizmente, cerca de $30 \%$ das crianças livres de crises por 1 a 2 anos recorrerão quando a medicação é retirada. (BERG et al., 1994; TENNISON et al., 1994; DOOLEY et al., 1996). Na prática clínica, presume-se que o controle das crises seja recuperado rapidamente com a reintrodução da medicação. Se o risco de as crises recomeçarem e se tornarem intratáveis for significativo, então a abordagem para a interrupção do fármaco deve ser reconsiderada (CAMFIELD et al., 2005).

A retirada de fármacos é uma expectativa para pacientes e familiares com epilepsia, tanto para aqueles em tratamento clínico, como para os submetidos ao tratamento cirúrgico. Além da atividade ictal recorrente e da atividade interictal, que apresentam efeito deletério sobre o cérebro em desenvolvimento, o uso de FAEs também pode gerar efeitos danosos ao desenvolvimento do sistema nervoso central. A cirurgia de epilepsia é um tratamento altamente eficaz e durável para controle de vários tipos específicos de epilepsia refratária (TÉLLEZ-ZENTENO et al., 2005; WIEBE et al., 2001) e, em muitos casos, permite redução ou retirada de fármacos minimizando os efeitos nocivos ao desenvolvimento neuropsicomotor do paciente.

Após a cirurgia, caso paciente não apresente novas crises, deve-se analisar cuidadosamente a possibilidade de redução ou interrupção dos FAEs (BERG et al., 2004). Entretanto, não há definição, baseada em evidências científicas claras, para orientar a modificação de FAEs no período PO. Em geral, a decisão de redução ou retirada de FAEs basea-se em práticas locais de cada serviço de epilepsia, sendo essas práticas altamente 
variáveis. Em uma revisão não sistemática, foram avaliados pacientes submetidos à cirurgia do lobo temporal, com acompanhamento em curto e longo prazos, que ficaram livres de crises e cujos FAEs foram retirados (SCHILLER et al., 2000; SCHMIDT; LOSCHER , 2003). Nesta revisão demonstrou-se que aproximadamente um terço dos pacientes ficou livre de crises e sem FAEs, um terço ficou controlado com FAEs, e um terço continuou a ter crises mesmo com FAEs. Ainda nesta revisão, verificou-se que a maioria dos estudos sobre esse tema é retrospectiva, não controlada; poucos estudos são prospectivos e nenhum é cego; poucos demonstraram resultados com mais de 5 anos de seguimento. Os resultados são variáveis e a maioria se refere à epilepsia de lobo temporal. Todos esses aspectos são limitantes para a interpretação e aplicação de protocolos de retirada de fármacos (SCHMIDT; LOSCHER, 2003).

Schiller e colaboradores, em 2000, publicaram um estudo em que avaliaram retrospectivamente os resultados de retirada de FAEs após cirurgia de epilepsia e constataram que a recorrência de crise ocorreu em $26 \%$ dos pacientes após 5 anos de cirurgia, enquanto a recorrência foi de 7\% naqueles que não interromperam FAEs. Já Berg e colaboradores (2006), em um estudo prospectivo, demonstraram que as crises recorreram em 32\% daqueles que diminuíram ou interromperam FAEs e em 45\% dos que não retiraram e/ou diminuíram (SCHILLER et al.,2000; BERG et al., 2006).

Não há uma concordância entre os epileptólogos sobre o tempo necessário para manutenção de FAEs no período pós operatório. Em uma pesquisa envolvendo epileptólogos americanos, 62\% acreditavam que os pacientes deveriam permanecer com FAEs por pelo menos 2 anos antes de considerar a descontinuação, mas os aspectos assistenciais em termos práticos não foram explorados nesse estudo (BERG et al., 2007). Considerando que após a cirurgia de epilepsia pacientes permenecem sem crises possibilitando a retirada ou redução dos FAEs, questiona-se sobre os fatores que comumente devem ser considerados como preditores para que a retirada de FAE seja bem-sucedida. Por exemplo, um estudo controlado evidenciou que a interrupção de FAEs não teve impacto na remissão de crises, e fatores como auras persistentes, uso de EEG intracraniano, tipo de lesão ou localização da ressecção não afetaram os resultados das crises após a interrupção dos FAEs (BERG et al., 2006). McLachlan e Maher propuseram que uma meta da cirurgia de epilepsia é a de transformar a politerapia em monoterapia. Eles sugeriram que se a monoterapia é usada antes da cirurgia, os FAEs poderiam permanecer inalterados ou uma pequena redução poderia ser tentada, aguardando pelo menos seis meses antes de reduzir os FAEs e, pelo menos, dois anos antes de 
parar todos os medicamentos em pacientes isentos de crises. Uma abordagem mais cautelosa é sugerida para cirurgia extratemporal (MCLACHLAN; MAHER, 2000).

Tellez-Zenteno e colaboradores (2007) fizeram uma metanálise de seguimento PO de longo prazo, explorando uso de fármacos após a cirurgia. Suas descobertas foram um pouco menos favoráveis do que as de Schmidt e Loscher (2003). Para todos os tipos de cirurgia, no longo prazo, 22\% (95\% IC, 18-23\%) dos pacientes foram curados e 20\% (IC 95\%, 18-23\%) estavam sem FAEs (com ou sem convulsões); 41\% (IC 95\%, 37-45\%) estavam em monoterapia e 31\% (IC 95\%, 27-35\%) estavam em politerapia. Os resultados relativos aos FAEs variaram por tipo de cirurgia: após a cirurgia do lobo temporal, 20\% (IC 95\%, 17-23\%) foram curados, 14\% (IC 95\%, 11-17\%) estavam livres de FAEs, 50\% (IC 95\%, 45-55\%) estavam em monoterapia e 33\% (IC 95\% 29-38\%) estavam em politerapia (TÉLLEZZENTENO et al.,2007).

Usando uma abordagem semelhante, Berg e colaboradores, 2007 exploraram aspectos práticos em relação à descontinuação de FAEs após a cirurgia de epilepsia bem sucedida de epileptologistas canadenses. Nesta exploração foi avaliado o tempo que os médicos esperavam, após a cirurgia, para reduzir os fármacos e foram verificados fatores preditores que favoreciam a redução dos FAEs (BERG et al., 2007). Fatores que são contrários à redução de FAEs também foram avaliados. Nos inúmeros estudos sobre descontinuação de fármacos há divergências, entre pesquisadores, sobre qual seria o teste usado para determinar a retirada ou redução de FAEs, sendo que alguns consideram o EEG como o determinante para retirada de FAEs, enquanto outros consideram ressonância magnética, nível sérico de fármacos, corroborando com a informação que a variação na prática clínica é determinada pelas diferenças nos padrões locais dos sistemas de saúde (TÉLLEZ-ZENTENO et al., 2012).

No que tange às hemisferotomias, a literatura é mais escassa, constando esse tópico manejo de FAEs no PO - como parte das séries cirúrgicas de hemisferotomia. Relata-se a redução em dose e em número de medicações em uso e a suspensão em 26,3 a 55\% dos pacientes, procedida naqueles livres de crises a partir de seis meses ou de dois anos da cirurgia, seguindo parâmetros eletrográficos. (CATS et al., 2007; JONAS et al., 2004; KOSSOFF et al., 2003; LETTORI et al., 2008; PULSIFER et al., 2004; TERRABUSTAMANTE et al., 2007) .

O risco de recorrência de crises após retirada ou redução de FAEs pode estar relacionado com certos fatores prognósticos descritos por alguns autores. Hoppe e colaboradores (2006) revelaram que os eventos epilépticos pós-cirúrgicos antes da tentativa de retirada de FAE aumentaram significativamente a probabilidade de recorrência de eventos 
epiléticos após a retirada ou diminuição (HOPPE et al., 2006). Além disso, alguns estudos verificaram que o risco de recorrência foi maior em pacientes com lesões multifocais, anormalidades no EEG PO, ressecção incompleta da lesão anatômica, resultado de anatomopatológico, história prévia de status epiléptico, retardo mental, maior número de FAEs utilizados no pré-operatório, idade de início das crises, duração da epilepsia e cirurgia prévia ineficaz ( TELLEZ-ZENTENO et al., 2012; BOSHUISEN et al.,2012; DEVLIN et al., 2003; JONAS et al., 2004; KOSSOFF et al., 2003; VINING et al., 1997; FLACK et al., 2008; PEACOCK et al., 1996; TERRA-BUSTAMANTE et al., 2007).

\subsection{Desenvolvimento e cognição}

A crise epiléptica é a principal manifestação da epilepsia na infância, mas, não menos importante ou limitante, é a série de comorbidades que acompanham as crises, caracterizando as síndromes epilépticas. Cerca de metade das epilepsias que acometem a faixa pediátrica cursam com graus variáveis de atraso de desenvolvimento, déficit cognitivo, transtorno de aprendizagem, de comportamento e problemas psiquiátricos e psicossociais (ÇATALTEPE et al., 2010). Assim, nas crianças os objetivos com a cirurgia são o controle das crises epilépticas com mínima ou nenhuma repercussão funcional (sequela neurológica), a interrupção do curso catastrófico de algumas epilepsias, a retomada ou manutenção do desenvolvimento, a melhora cognitiva e do comportamento, com possibilidades de desempenho escolar (CROSS 2002; DODRILL et al., 1980; DUCHOWNY et al., 1998; DUNKLEY et al., 2011) .

No cérebro imaturo, o potencial efeito deletério das repetitivas crises epilépticas, das descargas epilépticas e de FAEs no desenvolvimento neurológico da criança, junto à maior suscetibilidade aos danos e à maior capacidade de reabilitação, dada a plasticidade, tornam a definição do momento cirúrgico uma variável ímpar, que pode repercutir diretamente nos resultados.

Em algumas séries de hemisferotomia, a maior parte das crianças apresentava atraso do desenvolvimento ou déficit cognitivo instalado, dificultando a aplicação de testes adequados para a faixa etária e daqueles específicos para determinadas funções corticais. Os resultados de uma forma global são encorajadores, evidenciando um padrão de estabilização e, menos frequentemente, de melhora às avaliações pós-cirúrgicas quando comparadas às préoperatórias (BASHEER et al., 2007; DEVLIN et al., 2003; DI ROCCO et al., 2006; JONAS et al., 2004; LETTORI et al., 2008) . A série mais significativa foi a de Pulsifer et al.(2004). Foram avaliadas 71 crianças antes da cirurgia e 53 no PO de uma média de 5,4 anos. A média 
do QI antes da cirurgia foi 59, com piores resultados para o grupo com diagnósticos de MDC. A avaliação comparativa após a intervenção cirúrgica evidenciou manutenção dos parâmetros cognitivos, do grau de desenvolvimento e adaptação funcional na maior parte dos pacientes, com pouca melhora ou piora na avaliação longitudinal. Pacientes foram agrupados por etiologias e por lado do hemisfério operado, sem diferença estatística entre os grupos, salvo exceção os pacientes com encefalite de Rasmussen no hemisfério cerebral esquerdo, que apresentaram piores resultados para inteligência global e linguagem em relação aos que operaram o hemisfério cerebral direito (PULSIFER et al., 2004) .

Distúrbio comportamental nas crianças com lesão hemisférica, associado ou não a crises epilépticas, já havia sido observado por Krynauw, em 1950. Foram inclusive operadas duas crianças por distúrbio de comportamento sem aparentes crises epilépticas, com resultados satisfatórios (KRYNAUW et al., 1950) . Wilson, em 1970, relatou alterações comportamentais em $72 \%$ dos seus casos (WILSON 1970a) . Devlin e colaboradores, em 2003, referiram melhora do comportamento em 11 das 12 crianças com esta queixa prévia à cirurgia. Lettori e colaboradores, em 2008, observaram na avaliação pré-operatória alteração comportamental em oito crianças, com melhora em cinco, estabilidade em duas e piora em uma como resultado cirúrgico. Os pacientes que se beneficiaram no quesito comportamento estavam em remissão das crises. Ambas as séries referiram ainda piora do comportamento na avaliação pós-operatória no total de seis crianças sem queixas comportamentais prévias. Esta observação foi feita novamente em crianças livres de crise. Discute-se que a aparente piora comportamental não poderia de fato representar uma melhora clínica, tornando a criança mais ativa, participativa, distante do contexto de crises recorrentes e do uso excessivo de medicação (DEVLIN et al., 2003; LETTORI et al., 2008) . Em todas as séries, o comportamento das crianças foi avaliado por meio da observação dos médicos e psicólogos assistentes, pela informação dos pais, seja por entrevistas ou questionários gerais e, mais raramente específicos, a exemplo do Child Behavior Checklist (DEVLIN et al., 2003; KRYNAUW 1950; LETTORI et al., 2008; O'BRIEN et al., 2006; PULSIFER et al., 2004; WILSON 1970a). A análise da QV foi realizada por alguns autores de forma não detalhada nas publicações. Foram utilizados instrumentos gerais, não validados, aplicados como rotina nos centros ou direcionados para os estudos em particular, evidenciando melhora geral após a intervenção cirúrgica quando comparado com os dados pré-operatórios. Não foram especificadas as variáveis implicadas e a relação com o controle das crises (DEVLIN et al., 2003; FLACK et al., 2008; KOSSOFF et al., 2003; VINING et al., 1997) . Pulsifer et al., 2004, incluíram a análise de QV na sua avaliação através de uma entrevista estruturada com o 
cuidador e, se possível, com o próprio paciente, contemplando aspectos como frequência de crises, uso de FAE, nível educacional e ajuste de vida diária. A maioria dos pacientes e cuidadores manifestaram satisfação com a evolução no PO e apenas 8,5\% relataram algumas reservas. As respostas foram homogêneas entre as diferentes etiologias, independente do controle de crises e do uso de FAEs (PULSIFER et al., 2004).

$\mathrm{O}$ resultado desejado para o paciente com epilepsia, submetido à cirurgia, é ficar livre de crise e sem uso de FAEs. Para muitos pacientes a esperança de descontinuar o uso de FAEs é um dos principais objetivos da cirurgia, mas a questão de saber quando e se os FAEs devem ser reduzidos ou retirados depois da cirurgia permanece sem resposta. Nenhum consenso ou diretriz está disponível. Nesse estudo, a finalidade é demonstrar manejo de FAEs em pacientes após a hemisferotomia e verificar o desfecho cognitivo e de desenvolvimento destes pacientes após cirurgia e modificação de FAEs, considerando fatores que possam influenciar neste manejo de FAEs em um país com as características do Brasil (país continental em que há dificuldade de acesso aos centros especializados em cirurgia de epilepsia, além da condição socioeconômica da população). 


\section{OBJETIVOS}

\subsection{Objetivo geral}

Verificar se a hemisferotomia foi efetiva para retirada ou redução de FAEs em pacientes classificados como Engel I no Hospital das Clínicas da Faculdade de Medicina de Ribeirão Preto (HCFMRP).

\subsection{Objetivos específicos}

- Verificar se a hemisferotomia foi eficaz para o controle de crises em pacientes operados no HCFMRP em período determinado;

- Observar o manejo de FAEs, em curto e longo prazos, nos pacientes submetidos à hemisferotomia no HCFMRP;

- Verificar o intervalo mínimo para descontinuação de FAEs após hemisferotomia no HCFMRP;

- Verificar se houve recorrência de crises decorrentes da descontinuação de FAEs após hemisferotomia no HCFMRP;

- Analisar desfechos cognitivo e de desenvolvimento em pacientes livres de crises após hemisferotomia no HCFMRP;

- Verificar desfechos cognitivos e de desenvolvimento e sua potencial associação com redução de FAEs em pacientes cujos FAEs foram reduzidos ou retirados após hemisferotomia no HCFMRP. 


\section{MATERIAL E MÉTODO}

Estudo realizado de forma retrospectiva, através da revisão e análise de prontuários e de banco de dados de pacientes crianças e adolescentes (com idade inferior a 19 anos no momento da cirurgia), submetidos a cirurgias de hemisferotomia para tratamento de epilepsia refratária no Centro de Cirurgia de Epilepsia de Ribeirão Preto - CIREP - Hospital das Clínicas, Faculdade de Medicina de Ribeirão Preto da Universidade de São Paulo (FMRPUSP), entre os anos de 1995 e 2015.

\subsection{Critérios de inclusão e exclusão}

Estabeleceram-se os seguintes critérios de inclusão para a composição da amostra:

- Registro de dados pessoais, histórias clínica e cirúrgica completas nos prontuários médicos;

- Avaliação pré-operatória e cirurgia realizadas no CIREP;

- Período de seguimento PO mínimo de dois anos;

- Avaliação histopatológica realizada.

Foram excluídos os prontuários cuja avaliação pré-operatória não apresentava exame de neuroimagem

\subsection{Rotina de avaliação pré-operatória no CIREP}

Todos os pacientes apresentavam epilepsia refratária ao tratamento medicamentoso e foram submetidos ao programa de avaliação pré-operatório composto por avaliação clínica neurológica, com ênfase no diagnóstico e tratamento da epilepsia, monitorização prolongada por vídeo-eletroencefalograma (V-EEG) e exame de ressonância magnética (RM).

Avaliações complementares estão disponíveis no serviço, porém não são aplicadas a todos os pacientes, considerando necessidades e disponibilidades. Constam de avaliações complementares - Tomografia Computadorizada por emissão de fóton único (SPECT), RM funcional e avaliações clínicas - realizadas pelas equipes de neuropsicologia, psiquiatria, assistência social, fonoaudiologia, fisioterapia, fisiatria, terapia ocupacional e nutrição. 
Os casos dos pacientes foram discutidos por equipe interdisciplinar, composta pelo menos por médicos neuroclínicos, neurocirurgiões e neurorradiologistas para elaboração das hipóteses diagnósticas e tomada de decisão para realização da hemisferotomia.

Os outros profissionais envolvidos na avaliação pré-operatória também participam desse processo de estratégia terapêutica, seja presencialmente ou indiretamente através do envio das avaliações realizadas.

Em sequência, a decisão da equipe é discutida com familiares ou responsáveis, considerando a compreensão dos objetivos cirúrgicos, a necessidade de manutenção do tratamento medicamentoso a curto e médio prazos e aceitação da família dos riscos cirúrgicos e dos déficits neurológicos esperados a partir do procedimento.

\subsection{Rotina de avaliação pós-operatória no CIREP}

O material ressecado no procedimento cirúrgico é enviado para análise histopatológica.

Após a hemisferotomia, os pacientes permaneceram em unidades de terapia intensiva e/ou em leitos de enfermaria, por vezes por tempo prolongado (semanas) para início da reabilitação intra-hospitalar.

Os FAEs em uso no período pré-cirúrgico foram em geral mantidos no período PO. Estes FAEs ficaram suspensos no dia do procedimento, com reintrodução no primeiro dia PO; nesse intervalo foram utilizados fármacos através de via endovenosa, sendo a fenitoína o fármaco preferencialmente utilizado no caso de ausência de alergia medicamentosa.

Todos os pacientes foram avaliados no período PO por equipes clínica, neurocirúrgica e, quando possível, neuropsicológica, psiquiátrica e assistência social. Quando necessário e disponível, as demais equipes supracitadas procederam reavaliações. Conforme a disponibilidade do paciente, consultas sucessivas ambulatoriais foram realizadas, periodicamente, a partir do procedimento cirúrgico.

A avaliação ambulatorial é realizada com base nos dados clínicos, desenvolvimento e reabilitação, porém, com ênfase para o controle das crises epilépticas e para o tratamento medicamentoso.

Para os pacientes submetidos a mais de um procedimento cirúrgico, a última intervenção foi considerada o marco para esse estudo.

A procedência dos pacientes foi subdividida em três categorias seguintes: 
a) Ribeirão Preto e sua região de cobertura determinada pela divisão administrativa da Secretaria de Estado da Saúde de São Paulo através dos Departamentos Regionais de Saúde (DRS);

b) Estado de São Paulo, excluídas áreas sob cobertura do DRS de Ribeirão Preto;

c) Outros estados - com auxílio dos programas nacionais do Sistema Único de Saúde (SUS) - Central Nacional de Regulação de Alta Complexidade (CNRAC) e Tratamento Fora de Domicílio (TFD).

Todos os dados obtidos desde a admissão da criança no programa de cirurgia de epilepsia infantil ficaram armazenados em prontuários físicos ou eletrônicos e sob a forma de banco de dados elaborados pela equipe clínica.

\subsection{Variáveis analisadas}

As seguintes variáveis categóricas foram analisadas para cada paciente:

- Sexo;

- Etiologia - categorização em três grupos a partir da neuroimagem e da histopatologia:

- Malformação do desenvolvimento cortical (MDC): distúrbios de proliferação, migração ou organização (BARKOVICH et al., 2001) ;

- Lesões adquiridas e estáticas: lesões hemorrágicas, isquêmicas, traumáticas, glióticas, infecciosas;

- Doenças progressivas: encefalite de Rasmussen e síndrome de Sturge-Weber.

- Frequência de crises prévia à cirurgia, categorizada em:

a) Estado de mal epiléptico (EME) ou epilepsia parcial contínua (EPC);

b) Crises diárias;

c) Crises semanais;

d) Crises mensais.

- Gravidade do comprometimento cognitivo prévio à cirurgia; presença de deficiência mental grave/ profunda;

- Lado do hemisfério operado;

- Procedência do paciente - subdividida em três categorias seguintes:

a) Ribeirão Preto e sua região de cobertura - DRS XIII;

b) Estado de São Paulo, excluídas áreas sob cobertura do DRS de Ribeirão Preto; 
c) Outros estados.

- Evolução do desfecho de crises ao longo do tempo, conforme descrito em item referente;

- Dados comparativos da avaliação neuropsicológica pré-operatória versus PO, categorizados em:

a) Melhora;

b) Manutenção;

c) Piora.

- Número absoluto de FAEs utilizados previamente ao tratamento cirúrgico;

- Número absoluto de FAEs utilizados no período PO, discriminando o PO imediato (POI) e períodos de 6 meses, 1 ano, 2 anos, 5 anos, 10 anos e último retorno;

- Número percentual de FAEs utilizados no período PO, discriminando o PO imediato (POI) e períodos de 6 meses, 1 ano, 2 anos, 5 anos, 10 anos e último retorno, em relação ao número absoluto de FAEs em uso pré-operatório;

- Número de pacientes cujas doses de FAEs foram reduzidas;

- Número de pacientes que tiveram o número de FAEs reduzidos;

- Número de pacientes cujos FAEs foram completamente retirados;

- Número de pacientes cujos FAEs foram aumentados em número e/ou dose;

- Índice relativo de dose de FAEs (utilizando-se da dose por $\mathrm{kg}$ de peso), discriminando o PO imediato (POI) e períodos de 6 meses, 1 ano, 2 anos, 5 anos, 10 anos e último PO. Esse índice consiste na somatória em valores percentuais para cada medicamento; aos FAEs utilizados no pré-operatório atribui-se valor de $100 \%$ para dose por $\mathrm{kg}$ de cada medicação; nas demais avaliações são conferidos valores percentuais relativos ao que era administrado no pré-operatório. Ao se introduzir um novo FAE, um novo valor de $100 \%$ é atribuído a essa medicação, de modo que esse se torne referência para números relativos em avaliações sucessivas. No caso de omissão de dados de peso do paciente ou de dose por kg de peso, esse paciente e/ou período analisado será excluído desse item. Para fins de ilustração de como procedemos a esse cálculo seguem exemplos de pacientes demonstrados no quadro 1.

Quadro 1 - Exemplo do esquema de FAE utilizado por um paciente (paciente 32) para ilustrar o cálculo do Índice relativo de dose de FAEs, CIREP - HCFMRP. 


\begin{tabular}{|c|c|c|c|c|c|c|c|}
\hline $\begin{array}{c}\text { Pré- } \\
\text { operatório }\end{array}$ & PO & $\mathbf{6}$ meses & $\mathbf{1}$ ano & $\mathbf{2}$ anos & $\begin{array}{c}\mathbf{5} \\
\text { anos }\end{array}$ & $\begin{array}{c}\mathbf{1 0} \\
\text { anos }\end{array}$ & $\begin{array}{c}\text { Último } \\
\text { retorno }\end{array}$ \\
\hline $100 \%$ & $125 \%$ & $116 \%$ & $85 \%$ & $37 \%$ & 0 & - & 0 \\
\hline $\begin{array}{c}\text { Fenobarbital } \\
4 \mathrm{mg} / \mathrm{kg} / \mathrm{dia}\end{array}$ & $\begin{array}{c}\text { Fenobarbital } \\
5 \mathrm{mg} / \mathrm{kg} / \mathrm{dia}\end{array}$ & $\begin{array}{c}\text { Fenobarbital } \\
6 \mathrm{mg} / \mathrm{kg} / \mathrm{dia}\end{array}$ & $\begin{array}{c}\text { Fenobarbital } \\
4,6 \mathrm{mg} / \mathrm{kg} / \mathrm{dia}\end{array}$ & $\begin{array}{c}\text { Fenobarbital } \\
4,5 \mathrm{mg} / \mathrm{kg} / \mathrm{dia}\end{array}$ & 0 & - & 0 \\
\hline- & $\begin{array}{c}\text { Fenitoína } \\
5 \mathrm{mg} / \mathrm{kg} / \text { dia }\end{array}$ & - & - & - & - & - & - \\
\hline $\begin{array}{c}\text { Topiramato } \\
5 \mathrm{mg} / \mathrm{kg} / \text { dia }\end{array}$ & $\begin{array}{c}\text { Topiramato } \\
7,5 \mathrm{mg} / \mathrm{kg} / \text { dia }\end{array}$ & $\begin{array}{c}\text { Topiramato } \\
10 \mathrm{mg} / \mathrm{kg} / \text { dia }\end{array}$ & $\begin{array}{c}\text { Topiramato } \\
7 \mathrm{mg} / \mathrm{kg} / \mathrm{dia}\end{array}$ & - & - & - & - \\
\hline $\begin{array}{c}\text { Oxcarbazepina } \\
64 \mathrm{mg} / \mathrm{kg} / \mathrm{dia}\end{array}$ & - & - & - & - & - & - & - \\
\hline
\end{tabular}

Pré-operatório

Fenobarbital $=4 \mathrm{mg} / \mathrm{kg} / \mathrm{dia}=100 \%=1$

Topiramato $=5 \mathrm{mg} / \mathrm{kg} / \mathrm{dia}=100 \%=1$

Oxcarbazepina $=64 \mathrm{mg} / \mathrm{kg} / \mathrm{dia}=100 \%=1$

Total $=1+1+1=3=100 \%$

Pós-operatório (porcentagem de fármacos em relação ao pré-operatório)

Fenobarbital $=5 \mathrm{mg} / \mathrm{kg} / \mathrm{dia}=125 \%=1,25$

Topiramato $=7,5 \mathrm{mg} / \mathrm{kg} / \mathrm{dia}=150 \%=1,5$

Fenitoína $=5 \mathrm{mg} / \mathrm{kg} / \mathrm{dia}=100 \%=1$

Total $=1,25+1,5+1=3,75=3,75 / 3=125 \%$

6 meses (porcentagem de fármacos em relação ao pré-operatório)

Fenobarbital $=6 \mathrm{mg} / \mathrm{kg} / \mathrm{dia}=150 \%=1,5$

Topiramato $=10 \mathrm{mg} / \mathrm{kg} / \mathrm{dia}=200 \%=2$

Total $=1,5+2=3,5=3,5 / 3=116 \%$

1 ano (porcentagem de fármacos em relação ao pré-operatório)

Fenobarbital $=4,6 \mathrm{mg} / \mathrm{kg} / \mathrm{dia}=4,6 / 4=1,15=115 \%$

Topiramato $=7 \mathrm{mg} / \mathrm{kg} / \mathrm{dia}=7 / 5=1,4=140 \%$

Total $=1,15+1,4=2,55 / 3=85 \%$

2 anos (porcentagem de fármacos em relação ao pré-operatório)

Fenobarbital $=4,5 \mathrm{mg} / \mathrm{kg} / \mathrm{dia}=4,5 / 4=1,125=112,5 \%$

Total $=1,125=1,125 / 3=0,375=37,5 \%$

5 anos (porcentagem de fármacos em relação ao pré-operatório)

Zero fármacos

10 anos (porcentagem de fármacos em relação ao pré-operatório) 
Não se aplica

Último retorno (porcentagem de fármacos em relação ao pré-operatório)

Zero fármacos

- Intervalo desde a cirurgia à diminuição do primeiro FAE (entende-se por diminuição a redução de dose), categorizado em: a) POI a um mês PO; b) de um mês a um ano PO; c) de um a dois anos PO; d) além de dois anos PO;

- Intervalo desde a cirurgia à retirada de no mínimo um FAE, categorizado em: a) de POI a um ano PO; b) de um a dois anos PO; c) além de dois anos PO;

- Intervalo desde a cirurgia à retirada de todos os FAEs, categorizado em: a) de POI a um ano PO; b) de um a dois anos PO; c) além de dois anos PO;

- Recorrência de crises epilépticas ao longo da diminuição de um dos FAEs (pacientes que apresentaram crises epilépticas durante o período em que estavam sendo reduzidas as doses de FAEs);

- Recorrência de crises epilépticas após a diminuição de um dos FAE (pacientes apresentaram crises após ter sido reduzida dose de FAE e estar em uso de dose regular inferior à usada previamente);

- Recorrência de crises epilépticas após retirada de um dos FAE (pacientes que apresentaram crises após ter sido suspenso um FAE);

- Retomada do uso de FAE previamente utilizado nos pacientes com recorrência de crise após retirada;

- Controle de crises epilépticas após a reintrodução do FAE suspenso;

- Introdução de FAE não utilizado previamente nos pacientes com recorrência de crise;

- Controle de crises epilépticas após a introdução de FAE inédito.

\section{Variáveis numéricas:}

- Idade do paciente no ato cirúrgico;

- Idade de início da observação das crises epilépticas;

- Duração da epilepsia até o momento da intervenção cirúrgica.

\subsubsection{Análise clínica}

\subsubsection{Desfechos para controle de crises}


A avaliação e comparação dos resultados cirúrgicos dos pacientes quanto ao controle de crises no PO foram realizadas baseando-se na escala sugerida por Engel 1987 (ENGEL, 1996), adaptada para o uso passado o segundo ano da cirurgia. Foram considerados pacientes livres de crises aqueles categorizados na classe I dessa classificação (remissão de crises); melhora significativa de crises compreende a categorização nas classes II (redução de mais de $75 \%$ das crises) e III (redução de crises menor que 75\%); sem melhora de crises compreende a categorização na classe IV.

Foram definidos os anos primeiro, segundo, quinto e décimo PO como marcos para análise dessa série, com a finalidade de traçar o desfecho clínico para controle de crises a partir da cirurgia em curto e em longo prazos. Foi ainda considerado o desfecho cumulativo para os pacientes classe I no segundo ano PO, através dos dados da última consulta médica realizada no centro.

\subsubsection{Desfechos neuropsicológicos - desenvolvimento e dados cognitivos}

Os desfechos neuropsicológicos foram analisados através de avaliação com profissional qualificado, segundo um cronograma constituído por análises pré-operatória e pós-operatória de curto ou de longo prazos a depender da disponibilidade do profissional e do paciente. Para os fins comparativos desse estudo foram analisados exclusivamente os registros dos pacientes que tinham avaliações pré e pós-operatórias com instrumentos comparáveis ajustados para a idade e funcionalidade; resultados fornecidos no pré-operatório foram comparados com os resultados PO.

A avaliação neuropsicológica foi categorizada segundo a eficiência intelectiva da seguinte forma: 1) eficiência intelectiva normal; 2) eficiência intelectiva limítrofe; 3) deficiência intelectiva leve; 4) deficiência intelectiva moderada; 5) deficiência intelectiva grave. Os pacientes que não foram submetidos à avaliação neuropsicológica no momento pré e/ou pós-operatória foram categorizados como ignorados. Para realização dessa avaliação foram utilizados a Escala de Inteligência Wechsler para Crianças (WISC) e o instrumento para a avaliação da adaptação social Vineland Adaptive Behavior Scales, a qual deriva da Vineland Social Maturity Scale, escala elaborada por Doll em 1953, com as áreas de

funcionamento examinadas: comunicação, habilidades da vida cotidiana, socialização e habilidades motoras, havendo ainda uma área de problemas de comportamento (DUARTE, 2000; CRUZ, 2005). 
Foi então realizada uma análise comparativa entre os períodos do PO e a avaliação pré-operatória, com definição das seguintes categorias: melhora, piora ou manutenção da eficiência intelectual.

Além das variáveis listadas, potencialmente associadas aos possíveis desfechos para o desenvolvimento e capacidade cognitiva (melhora, estabilização ou piora), foi analisada ainda a remissão de crises, como possível fator prognóstico neuropsicológico.

\subsection{Considerações éticas}

O presente estudo foi aprovado pelo Comitê de Ética em Pesquisa do Hospital das Clínicas da Faculdade de Medicina de Ribeirão Preto da Universidade de São Paulo HCFMRP-USP, conforme parecer do processo CEP HCRP n ${ }^{\circ}$ 14607/2017. 


\section{RESULTADOS}

Foram analisados dados referentes a 120 crianças e adolescentes submetidos à hemisferotomia no HCFMRP durante os anos de 1995 a 2015, sendo que 66 (55\%) eram do sexo masculino e 54 (45\%) feminino. A idade atual dos sujeitos variou entre três e 36 anos (média de 19,26 \pm 9,69) no momento do estudo.

Nove sujeitos foram excluídos por carência de informações de laudos de exame histopatológico ou de neuroimagem e histórias clínica e cirúrgica suficientes nos prontuários médicos; outros 28 foram excluídos por tempo de seguimento inferior a dois anos. Restaram para análise 82 pacientes. Desses, 41 (50\%) eram do sexo masculino e 41 (50\%) eram do sexo feminino.

Em relação à frequência de crises desses pacientes, 22 (26,8\%) apresentaram estado de EME ou EPC antes da abordagem cirúrgica; 52 (63,5\%) crises diárias; 6 (7,3\%) crises semanais; $2(2,4 \%)$ crises mensais.

Esses pacientes eram fármaco-resistentes em uso médio de 3 FAEs, com variação de 1 a 5 .

Considerando o desfecho clínico favorável, com remissão ou redução significativa de crises (Engel classes I e II em conjunto), foram beneficiados: 76 pacientes (95\%) no primeiro ano PO, 76 (95\%) no segundo ano PO, 52 (74\%) no quinto ano PO e 71 (88,8\%) à última avaliação clínica. Foi observada remissão de crises (Engel classe I) em 44 pacientes (55\%) no primeiro ano PO, 44 (55\%) no segundo ano PO, em 28 (40\%) no quinto ano PO e em 38 (47,5\%) considerando a última avaliação clínica.

Para fins de avaliação do manejo dos FAEs em pacientes submetidos à hemisferotomia, foram considerados apenas aqueles indivíduos que ficaram livres de crises epilépticas passados dois anos do procedimento (Engel I no segundo ano PO). O número desses pacientes analisados, portanto, foi de 44 (100\%). O tempo médio de seguimento PO foi de 3,7 anos, variando de 2 a 19 anos.

Destes, 21(47,73\%) eram do sexo masculino e 23 (52,27\%) do feminino, com idade atual entre cinco e 36 anos (média de 16,68 $\pm 8,52$, mediana de 15) no momento do estudo.

Em relação à procedência dos pacientes, verificou-se que $6(13,63 \%)$ pacientes eram provenientes do DRS XIII, 4 (9,10\%) do estado de São Paulo, porém de outras localidades fora do DRS XIII e 34 (77,27\%) eram provenientes de outros estados da União (Tabela 1). 
Tabela 1 - Distribuição da procedência dos pacientes da pesquisa.

\begin{tabular}{lcclcc}
\hline \multicolumn{1}{c}{ Estado } & $\mathbf{n}$ & $\mathbf{\%}$ & \multicolumn{1}{c}{ Regiões } & $\mathbf{n}$ & $\mathbf{\%}$ \\
\hline Alagoas & 7 & 18,42 & DRS XIII & 6 & 13,63 \\
Amazonas & 1 & 2,63 & São Paulo & 4 & 9,10 \\
Bahia & 2 & 5,26 & Outros & 34 & 77,27 \\
Ceará & 2 & 5,26 & Total & $\mathbf{4 4}$ & $\mathbf{1 0 0 , 0 0}$ \\
Espirito Santo & 3 & 7,89 & & & \\
Minas Gerais & 8 & 21,05 & & \\
Paraíba & 1 & 2,63 & & \\
Paraná & 1 & 2,63 & & \\
Pernambuco & 1 & 2,63 & & \\
Rio de Janeiro & 6 & 15,79 & & \\
Rondônia & 1 & 2,63 & & \\
São Paulo & $\mathbf{4}$ & $\mathbf{1 0 , 5 3}$ & & \\
Sergipe & 1 & 2,63 & & \\
Total & $\mathbf{3 8}$ & $\mathbf{1 0 0 , 0 0}$ & & \\
Direção Regional de Saúde XIII - Ribeirão Preto & & & \\
Ribeirão Preto & 4 & 66,67 & & \\
Batatais & 1 & 16,67 & & \\
São Simão & 1 & 16,67 & & \\
Total & $\mathbf{6}$ & $\mathbf{1 0 0 , 0 0}$ & & \\
\hline
\end{tabular}

Fonte: Prontuários, CIREP - HCFMRP.

A idade de início das crises variou entre 0 e 159 meses (média de 42,57士42,12).

A média de idade no momento da cirurgia foi de 7,82 anos, com dois pacientes com idade inferior a um ano (4,54\%), 17 (38,64\%) pacientes entre um e cinco anos, 13 (29,55\%) pacientes entre seis e dez anos e $12(27,27 \%)$ pacientes com idade superior a 11 anos. A variação das idades foi de 10 meses a 18,33 anos (Tabela 2).

Tabela 2 - Distribuição da idade dos pacientes no momento da realização da cirurgia.

\begin{tabular}{lcc}
\hline \multicolumn{1}{c}{ Idade na cirurgia } & $\mathbf{n}$ & $\mathbf{\%}$ \\
\hline Menor de 1 ano & 2 & 4,54 \\
1-5 anos & 17 & 38,64 \\
6-10 anos & 13 & 29,55 \\
Maior de 11 anos & 12 & 27,27 \\
Total & 44 & $\mathbf{1 0 0 , 0 0}$ \\
\hline
\end{tabular}

Fonte: Prontuários, CIREP - HCFMRP. 
Tabela 3 - Distribuição da duração da epilepsia em categorias.

\begin{tabular}{lcc}
\hline \multicolumn{1}{c}{ Duração da epilepsia } & n & \% \\
\hline Menor de 12 meses & 6 & 13,64 \\
12-60 meses & 19 & 43,18 \\
Maior de 60 meses & 19 & 43,18 \\
Total & $\mathbf{4 4}$ & 100,00 \\
\hline Fonte: Prontuários, CIREP - HCFMRP. & &
\end{tabular}

No que tange à duração da epilepsia, 13,64\% (6) dos pacientes permaneceram menos de 12 meses com a epilepsia, 86,36\% (38) tiveram a duração da epilepsia maior que 12, sendo que metade desses apresentaram duração maior que 60 meses (Tabelas 3). A média de duração da epilepsia foi de 62,6 meses.

Observou-se que três $(6,82 \%)$ pacientes foram reabordados cirurgicamente. As etiologias categorizadas por meio de RM estão descritas na tabela 4.

Tabela 4 - Distribuição da etiologia categorizada por meio de ressonância magnética.

\begin{tabular}{lcc}
\hline Etiologia categorias: ressonância magnética & n & $\mathbf{\%}$ \\
\hline Malformação do desenvolvimento cortical & 17 & 38,64 \\
Causa adquirida & 13 & 29,55 \\
Causa progressiva & 14 & 31,82 \\
Total & $\mathbf{4 4}$ & $\mathbf{1 0 0 , 0 0}$ \\
\hline
\end{tabular}

Fonte: Prontuários, CIREP - HCFMRP.

Evidenciou-se que, dentre os casos de MDC, seis $(13,64 \%)$ dos sujeitos apresentaram HME na RM. Não foram evidenciados tumor em RM, sendo que $25(56,82 \%)$ das cirurgias de hemisferotomia foram realizadas do lado esquerdo e 19 do direito (43,18\%).

A frequência de crises desses pacientes no pré-operatório está demostrada na tabela 5.

Tabela 5 - Distribuição da frequência de crises no pré-operatório.

\begin{tabular}{lcc}
\hline Frequência de crise no pré-operatório & n & \% \\
\hline EME/EPC & 12 & 27,27 \\
Diária & 26 & 59,09 \\
Semanal & 5 & 11,36 \\
Mensal & 1 & 2,27 \\
Total & $\mathbf{4 4}$ & $\mathbf{1 0 0 , 0 0}$ \\
\hline
\end{tabular}

Fonte: Prontuários, CIREP - HCFMRP. 
Esses pacientes eram fármaco-resistentes em uso de combinações de FAEs; 13 pacientes usavam dois fármacos, 19 pacientes usavam três, nove pacientes estavam em uso de quatro e três indivíduos em uso de cinco fármacos (Tabela 6).

Tabela 6 - Número de fármacos antiepilépticos utilizados pelos pacientes no momento pré-operatório.

\begin{tabular}{lcc}
\hline $\begin{array}{c}\text { Número de Fármacos } \\
\text { antiepiléticos }\end{array}$ & n & \% \\
\hline Dois & 13 & 29,55 \\
Três & 19 & 43,18 \\
Quatro & 9 & 20,45 \\
Cinco & 3 & 6,82 \\
Total & $\mathbf{4 4}$ & $\mathbf{1 0 0 , 0 0}$ \\
\hline
\end{tabular}

Fonte: Prontuários, CIREP - HCFMRP.

Os resultados da classificação Engel estão demonstrados na tabela 7.

Tabela 7 - Engel ao longo do seguimento pós-operatório.

\begin{tabular}{|c|c|c|c|c|c|c|c|c|}
\hline \multirow{3}{*}{ Classe } & \multicolumn{8}{|c|}{ Engel } \\
\hline & \multicolumn{2}{|c|}{ Ano 1} & \multicolumn{2}{|c|}{ Ano 2} & \multicolumn{2}{|c|}{ Ano 5} & \multicolumn{2}{|c|}{ Último } \\
\hline & $\mathbf{n}$ & $\%$ & $\mathbf{n}$ & $\%$ & $\mathbf{n}$ & $\%$ & $\mathbf{n}$ & $\%$ \\
\hline Classe I & 36 & 81,82 & 44 & 100,00 & 22 & 50,00 & 29 & 65,92 \\
\hline Classe II & 6 & 13,64 & - & - & 8 & 18,18 & 13 & 29,55 \\
\hline Não se aplica & - & - & - & - & 8 & 18,18 & - & - \\
\hline Ignorado & 2 & 4,55 & - & - & 6 & 13,64 & 2 & 4,55 \\
\hline Total & 44 & 100,00 & 44 & 100,00 & 44 & 100,00 & 44 & 100,00 \\
\hline
\end{tabular}

Fonte: Prontuários, CIREP - HCFMRP.

Em relação ao número de fármacos usados no período $\mathrm{PO}$, os mesmos estão demonstrados na tabela 8 .

Tabela 8 - Distribuição do número de fármacos antiepilépticos utilizados no período pós-operatório.

\begin{tabular}{|c|c|c|c|c|c|c|c|c|c|c|c|c|c|c|}
\hline \multirow{3}{*}{$\begin{array}{l}\text { Número de } \\
\text { fármacos }\end{array}$} & \multicolumn{14}{|c|}{ Período pós-operatório } \\
\hline & \multicolumn{2}{|c|}{ Imediato } & \multicolumn{2}{|c|}{6 meses } & \multicolumn{2}{|c|}{1 ano } & \multicolumn{2}{|c|}{2 anos } & \multicolumn{2}{|c|}{5 anos } & \multicolumn{2}{|c|}{10 anos } & \multicolumn{2}{|c|}{ Último } \\
\hline & $\mathbf{n}$ & $\%$ & $\mathbf{n}$ & $\%$ & $\mathbf{n}$ & $\%$ & $\mathbf{n}$ & $\%$ & $\mathbf{n}$ & $\%$ & $\mathbf{n}$ & $\%$ & $\mathbf{n}$ & $\%$ \\
\hline Nenhum & - & - & - & - & - & - & - & - & 1 & 2,27 & 2 & 455 & 4 & 9,09 \\
\hline
\end{tabular}




\begin{tabular}{lcccccccccccccc} 
Um & - & - & 3 & 6,82 & 3 & 6,82 & 6 & 13,64 & 12 & 27,27 & 5 & 11,36 & 14 & 31,82 \\
Dois & 14 & 31,82 & 14 & 31,82 & 19 & 43,18 & 22 & 50,00 & 15 & 34,09 & 3 & 6,82 & 18 & 40,91 \\
Três & 19 & 43,18 & 19 & 43,18 & 17 & 38,64 & 12 & 2727 & 2 & 4,55 & 1 & 2,27 & 8 & 18,18 \\
Quatro & 9 & 20,45 & 4 & 9,09 & 2 & 4,55 & 1 & 2,27 & - & - & - & - & - & - \\
Cinco & 2 & 4,55 & - & - & - & - & - & - & - & - & - & - & - & - \\
Não se aplica & - & - & - & - & - & - & - & - & 9 & 20,45 & 31 & 70,45 & - & - \\
Ignorado & - & - & 4 & 9,09 & 3 & 6,82 & 3 & 6,82 & 5 & 11,33 & 2 & 4,55 & - & - \\
Total & $\mathbf{4 4}$ & $\mathbf{1 0 0 , 0 0}$ & $\mathbf{4 4}$ & $\mathbf{1 0 0 , 0 0}$ & $\mathbf{4 4}$ & $\mathbf{1 0 0 , 0 0}$ & $\mathbf{4 4}$ & $\mathbf{1 0 0 , 0 0}$ & $\mathbf{4 4}$ & $\mathbf{1 0 0 , 0 0}$ & $\mathbf{4 4}$ & $\mathbf{1 0 0 , 0 0}$ & $\mathbf{4 4}$ & $\mathbf{1 0 0 , 0 0}$ \\
\hline
\end{tabular}

Fonte: Prontuários, CIREP - HCFMRP.

Dos 44 pacientes avaliados, o tempo de seguimento clínico PO foi variável de três a 18 anos, média $8,61 \pm 5,20$, mediana 8 .

$\mathrm{O}$ intervalo da cirurgia à diminuição do primeiro FAE variou entre 0,002 e 4 anos, média de $0,896 \pm 1,36$, mediana 0,28 . No entanto, o intervalo da cirurgia e retirada de todos os FAEs, naqueles pacientes em que isso foi possível, variou entre 6,84 e 9 anos, média de $8 \pm 1,08$, mediana 8 .

O tempo de retirada do primeiro FAE variou em zero e 96 meses, média de 10 $\pm 37,30$, mediana 10 .

Em relação ao intervalo da retirada completa dos FAEs até a última consulta, variou de dois a quatro anos, média de $3 \pm 1,41$, mediana 3 .

A recorrência de crises epilépticas independente do manejo de FAEs foi evidenciada em $23(52,27 \%)$ dos sujeitos. O intervalo de recorrência pós-operatória foi entre 0,16 e 12

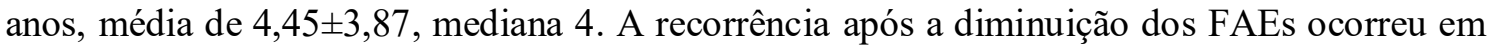
$3(13,04 \%)$ dos indivíduos e a recorrência ao longo da diminuição dos FAEs ocorreu em 7(30,43\%) pacientes; o intervalo de recorrência durante redução foi entre seis e 96 meses, média de 40,5 $\pm 41,38$, mediana 30 .

Quanto à recorrência após a retirada dos FAEs, foi evidenciada em $6(26,08 \%)$ dos indivíduos, com intervalo entre 0,25 e 9 anos, média de 3,52 $\pm 3,02$, mediana 3 .

Observou-se que $4(66,67 \%)$ pacientes, dentre os que tiveram FAEs retirados, retornaram o uso de FAEs prévios e 3 (75\%) obtiveram controle após reintrodução. Ainda, 13 pacientes que tiveram seus FAEs manejados no PO necessitaram de introdução de novos fármacos, sendo que quatro obtiveram controle após os novos fármacos.

Em relação aos exames neuropsicológicos pré-operatórios, os coeficientes de desenvolvimento (QD) e de inteligência (QI) foram avaliados em 31 pacientes. Treze pacientes não tiveram essa avaliação realizada. Dentre os pacientes avaliados, dois 
apresentaram eficiência intelectual normal, dois estavam em faixa limítrofe, oito pacientes apresentaram deficiência intelectual leve, 14 moderada e cinco, deficiência intelectual grave (Gráfico 1).

A avaliação através do Vineland foi realizada em 22(50,00\%) dos pacientes antes da abordagem cirúrgica. Nove (20,45\%) foram submetidos ao exame WISC e 13 (29,54\%) foram considerados ignorados por falta de informação em prontuário.

Gráfico 1 - Classificação pré-operatória do coeficiente de inteligência e de desenvolvimento após avaliação neuropsicológica ou avaliação de comportamento adaptativo.

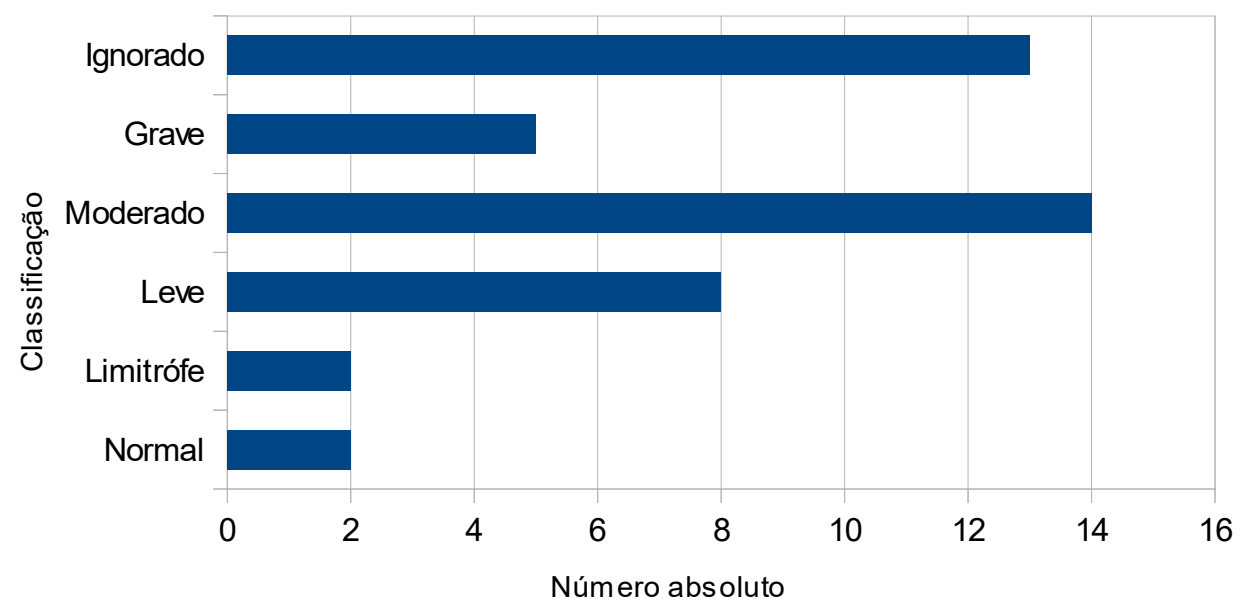

As avaliações neuropsicológicas no PO estão demonstradas no gráfico 2. Na avaliação neuropsicológica PO, os coeficientes de desenvolvimento (QD) e de inteligência (QI) foram avaliados em 31 pacientes. Treze pacientes não tiveram essa avaliação realizada. Dentre os pacientes avaliados, um apresentaram eficiência intelectual normal, três estavam em faixa limítrofe, dez pacientes apresentaram deficiência intelectual leve, 13 moderada e quatro, deficiência intelectual grave (Gráfico 2).

O Vineland pré-operatório foi realizado em 24 (77,41\%) dos pacientes. Cinco (16,13\%) foram submetidos a escala WISC e $13(29,54 \%)$ foram considerados ignorados por falta de informação em prontuário.

A avaliação neuropsicológica pré e pós-operatória foi realizada em 29 dos 44 pacientes. Em dez pacientes nenhuma avaliação foi realizada, em dois pacientes foi realizada apenas avaliação pré-operatória e em 3 apenas PO. 
Gráfico 2 - Classificação pós-operatória dos coeficientes de inteligência e de desenvolvimento após avaliação neuropsicológica ou avaliação de comportamento adaptativo.

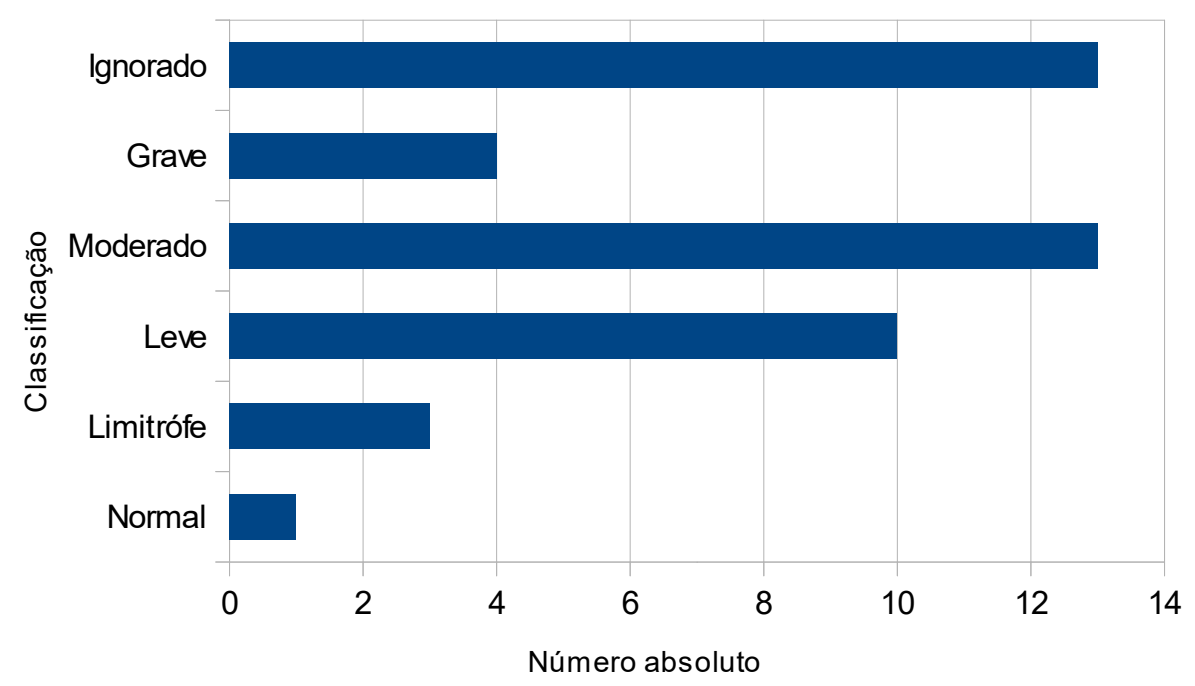

O tempo após a cirurgia no qual foi realizada a avaliação neuropsicológica variou de 0,25 a 16 anos, média de $3,58 \pm 4,13$, mediana 2,08 .

Quanto aos ganhos de desenvolvimento e cognitivo, QD e QI foram analisados após a intervenção cirúrgica e comparados com avaliação pré-operatória. A representação do gráfico 3 demonstra que, dos 29 pacientes que tiveram avaliação neuropsicológica pré e pósoperatória realizadas, a maioria (18 pacientes) apresentou eficiência intelectual mantida. Quatro pacientes apresentaram piora e sete apresentaram melhora. Dez pacientes, dos 44 pacientes, foram considerados ignorados por falta de dados no prontuário e cinco não tiveram seus dados comparados uma vez que possuíam apenas uma avaliação neuropsicológica, pré ou pós-operatória.

Gráfico 3 - Comparação entre os resultados das avaliações neuropsicológicas pré e pósoperatória.

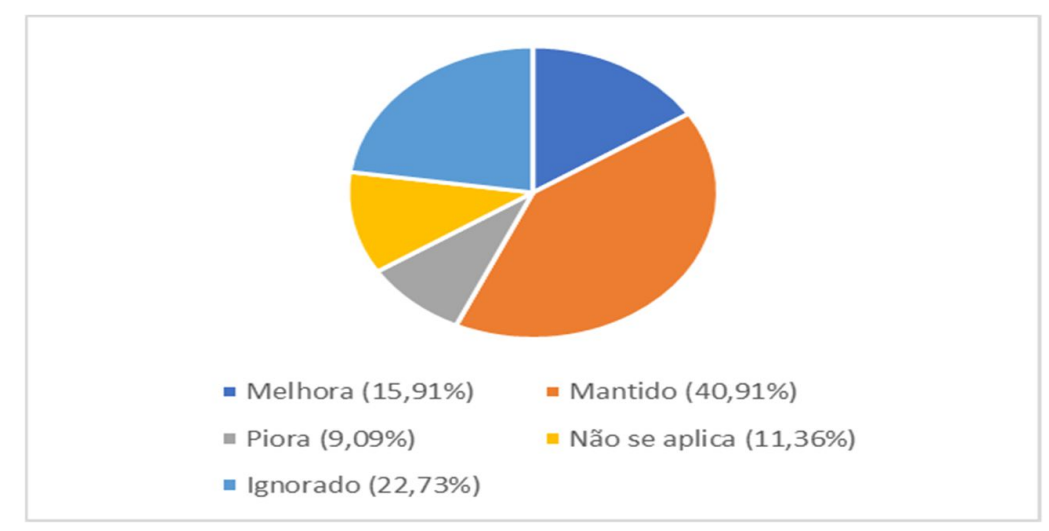


Foi possível verificar uma redução considerável do percentual de FAEs utilizados pelos pacientes quando comparados os períodos pré-operatório e PO em curto e longo prazos. Tais dados estão demonstrados na tabela 9.

Tabela 9 - Distribuição do percentual de retirada dos fármacos antiepilépticos no pós-operatório.

\begin{tabular}{|c|c|c|c|c|c|c|c|c|}
\hline \multirow{3}{*}{ Casos } & \multicolumn{8}{|c|}{ Estágios } \\
\hline & 1 & 2 & 3 & 4 & 5 & 7 & 8 & 9 \\
\hline & Pré-operatório & POI & $\begin{array}{c}6 \text { meses } \\
\text { PO }\end{array}$ & $\begin{array}{c}1 \text { ano } \\
\text { PO }\end{array}$ & $2 \operatorname{anos} P O$ & 5 anos PO & 10 anos $P O$ & Último retorno \\
\hline 1 & 100 & 100 & 66,7 & 66,7 & 66,7 & 33,3 & 33,3 & 33,3 \\
\hline 2 & 100 & 100 & 100 & 100 & 100 & 100 & - & 100 \\
\hline 3 & 100 & 100 & 100 & 66,7 & 33,3 & 33,3 & 100 & 100 \\
\hline 4 & 100 & 100 & 100 & 100 & 66,7 & 33,3 & 33,3 & 33,3 \\
\hline 5 & 100 & 200 & 150 & 150 & 100 & 100 & 100 & 150 \\
\hline 6 & 100 & 100 & 100 & 100 & 100 & 100 & 100 & 50 \\
\hline 7 & 100 & 100 & 66,7 & 66,7 & 66,7 & - & 33,3 & 66,7 \\
\hline 8 & 100 & 100 & 66,7 & 66,7 & 100 & 66,7 & - & 66,7 \\
\hline 9 & 100 & 100 & 100 & 100 & 100 & 33,3 & 33,3 & 33,3 \\
\hline 10 & 100 & 100 & 100 & 100 & 100 & 33,3 & 33,3 & 33,3 \\
\hline 11 & 100 & 66,7 & 133,3 & 100 & 100 & 66,7 & 66,7 & 66,7 \\
\hline 12 & 100 & 100 & 100 & 100 & 100 & 0 & - & 50 \\
\hline 13 & 100 & 100 & 100 & 100 & 66 & 66 & 0 & 0 \\
\hline 14 & 100 & 100 & 75 & 50 & 50 & 25 & 0 & 0 \\
\hline 15 & 100 & 100 & 100 & 100 & 100 & 100 & - & 100 \\
\hline 16 & 100 & 100 & 100 & 100 & 100 & 100 & - & 50 \\
\hline 17 & 100 & 100 & 0 & 100 & 100 & 66,7 & - & 66,7 \\
\hline 18 & 100 & 100 & 75 & 75 & 75 & 0 & - & 75 \\
\hline 19 & 100 & 100 & 50 & 50 & 50 & 50 & 0 & 0 \\
\hline 20 & 100 & 100 & 100 & 100 & 66,7 & 33,3 & - & 33,3 \\
\hline 21 & 100 & 100 & 100 & 100 & 100 & 100 & - & 100 \\
\hline 22 & 100 & 100 & 66,7 & - & 100 & - & - & 100 \\
\hline 23 & 100 & 100 & 100 & 100 & 50 & 50 & - & 50 \\
\hline 24 & 100 & 100 & 100 & 100 & 100 & - & - & 100 \\
\hline 25 & 100 & 100 & 100 & 100 & 133,3 & 100 & - & 100 \\
\hline 26 & 100 & 100 & 0 & 100 & 0 & 50 & - & 50 \\
\hline 27 & 100 & 100 & 50 & 50 & 50 & 50 & - & 50 \\
\hline 28 & 100 & 75 & 75 & 50 & 50 & 50 & - & 50 \\
\hline 29 & 100 & 100 & 75 & 50 & 50 & 33 & - & 25 \\
\hline 30 & 100 & 100 & 100 & 100 & 0 & 25 & - & 25 \\
\hline 31 & 100 & 100 & 66,7 & 66,7 & 33,3 & - & - & 0 \\
\hline 32 & 100 & 100 & 50 & - & - & 50 & - & 50 \\
\hline 33 & 100 & 80 & 60 & 60 & 60 & 40 & - & 40 \\
\hline 34 & 100 & 100 & 100 & 100 & 100 & 100 & - & 100 \\
\hline 35 & 100 & 75 & 75 & 75 & 75 & - & - & 75 \\
\hline 36 & 100 & 100 & - & - & 33,3 & - & - & 33,3 \\
\hline 37 & 100 & 100 & 33,3 & 66,7 & 66,7 & - & - & 66,7 \\
\hline 38 & 100 & 100 & 75 & 75 & 75 & - & - & 50 \\
\hline 39 & 100 & 100 & 60 & 60 & 40 & - & - & 40 \\
\hline 40 & 100 & 100 & 100 & 100 & 100 & - & - & 100 \\
\hline 41 & 100 & 66,7 & - & 66,7 & 66,7 & - & - & 66,7 \\
\hline 42 & 100 & 100 & 100 & 100 & 100 & - & - & 100 \\
\hline
\end{tabular}




\begin{tabular}{c|c|c|c|c|c|c|c|c}
43 & 100 & 100 & 60 & 60 & 40 & - & - & 40 \\
44 & 100 & 100 & 100 & 50 & 50 & - & - & 50 \\
Média & $\mathbf{1 0 0}$ & $\mathbf{9 9 , 2}$ & $\mathbf{8 1 , 7}$ & $\mathbf{8 3 , 5}$ & $\mathbf{7 2 , 4}$ & $\mathbf{5 5 , 2}$ & $\mathbf{4 4 , 4}$ & $\mathbf{5 8 , 4}$ \\
\hline
\end{tabular}

Fonte: Prontuários, CIREP - HCFMRP.

Representação dos resultados dos pacientes que ficaram livres de fármacos após a cirurgia, quanto ao percentual de retirada dos FAEs utilizados estão demonstrados nos gráficos 4, 5, 6 e 7 .

Gráfico 4 - Percentual retirada FAEs (caso 13), CIREP - HCFMRP, 2018.

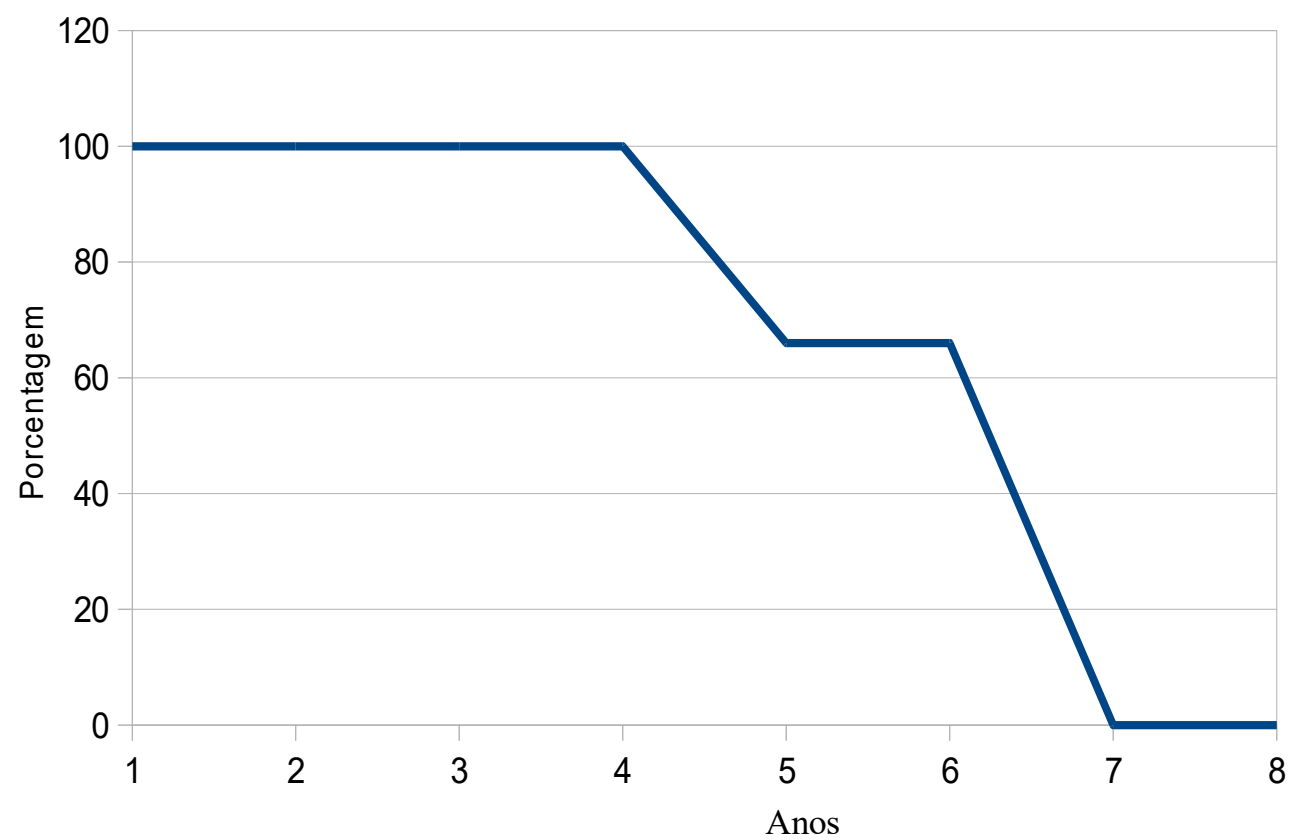

Gráfico 5 - Percentual retirada FAEs (caso 14), CIREP - HCFMRP, 2018.

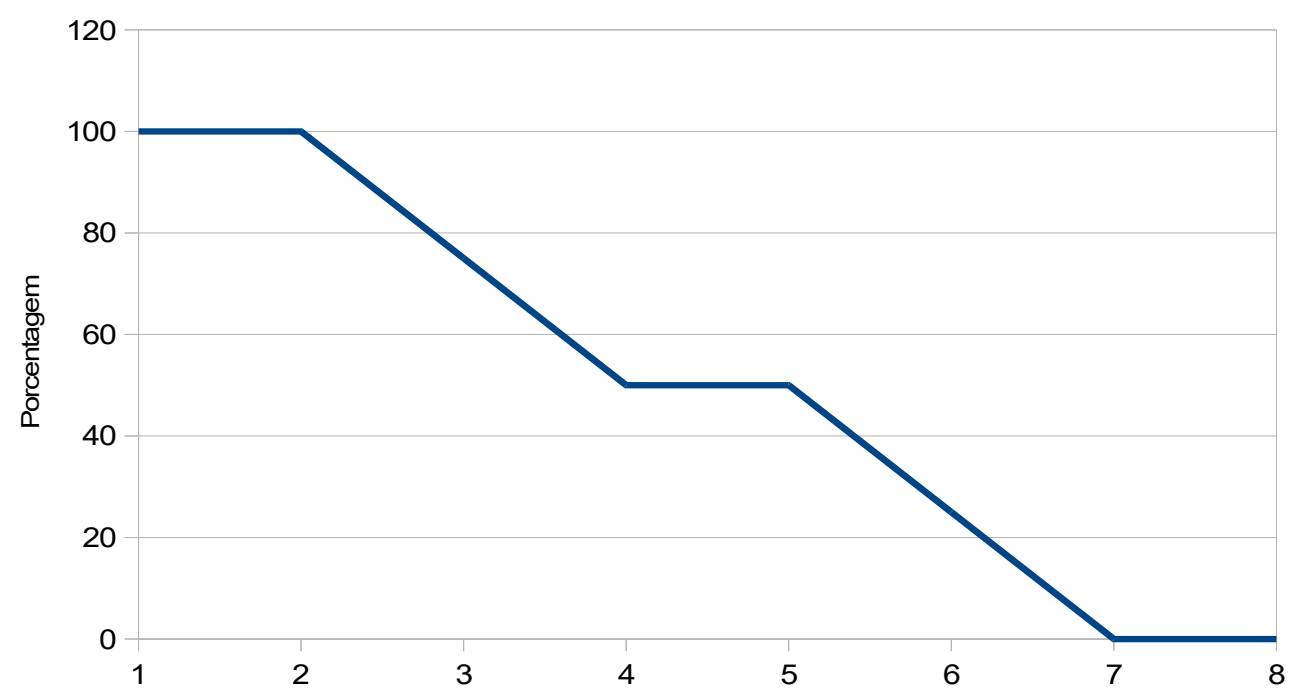


Anos

Gráfico 6 - Percentual retirada FAEs (caso 19), CIREP - HCFMRP, 2018.

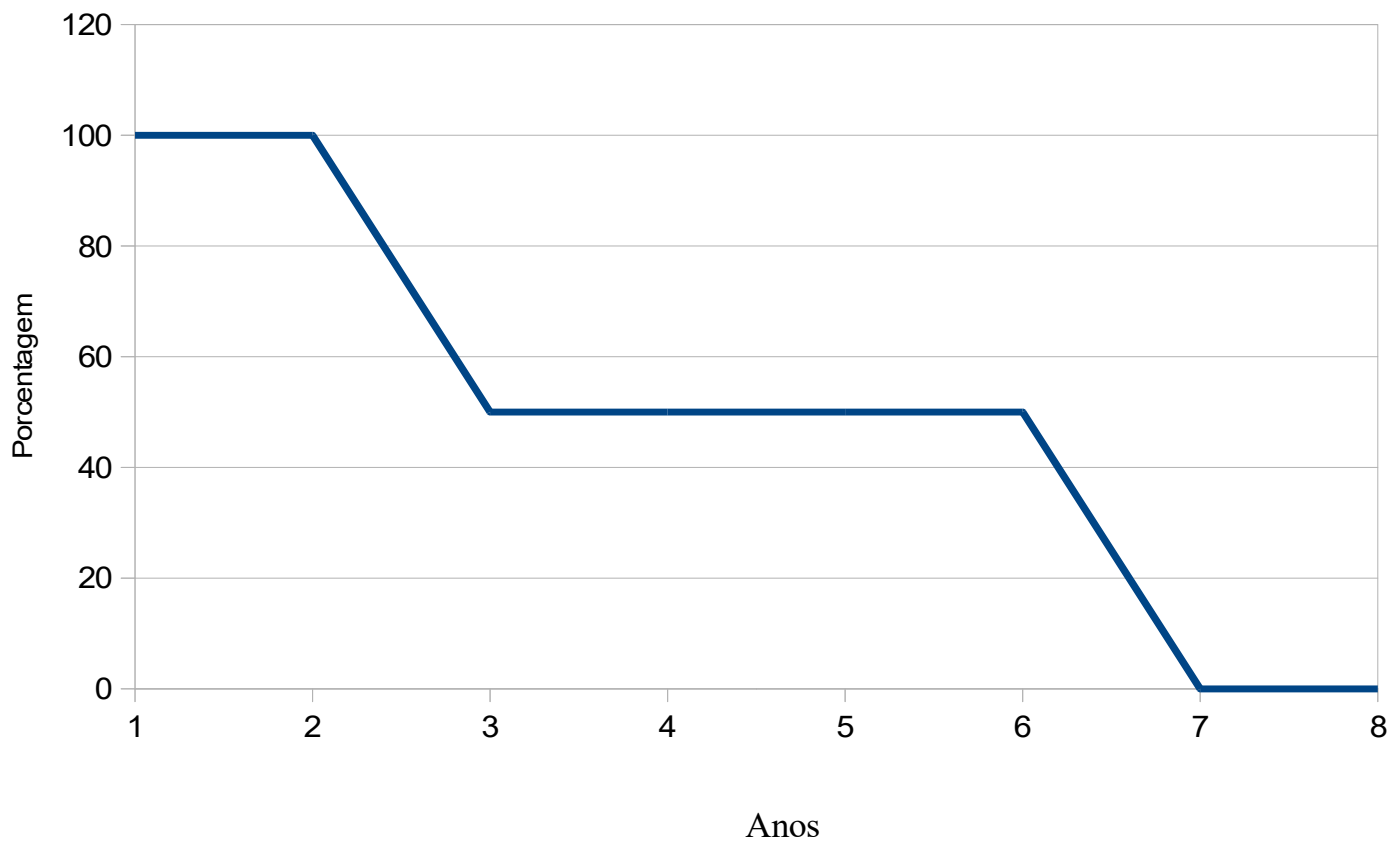

Gráfico 7 - Percentual retirada FAEs (caso 31), CIREP - HCFMRP, 2018.

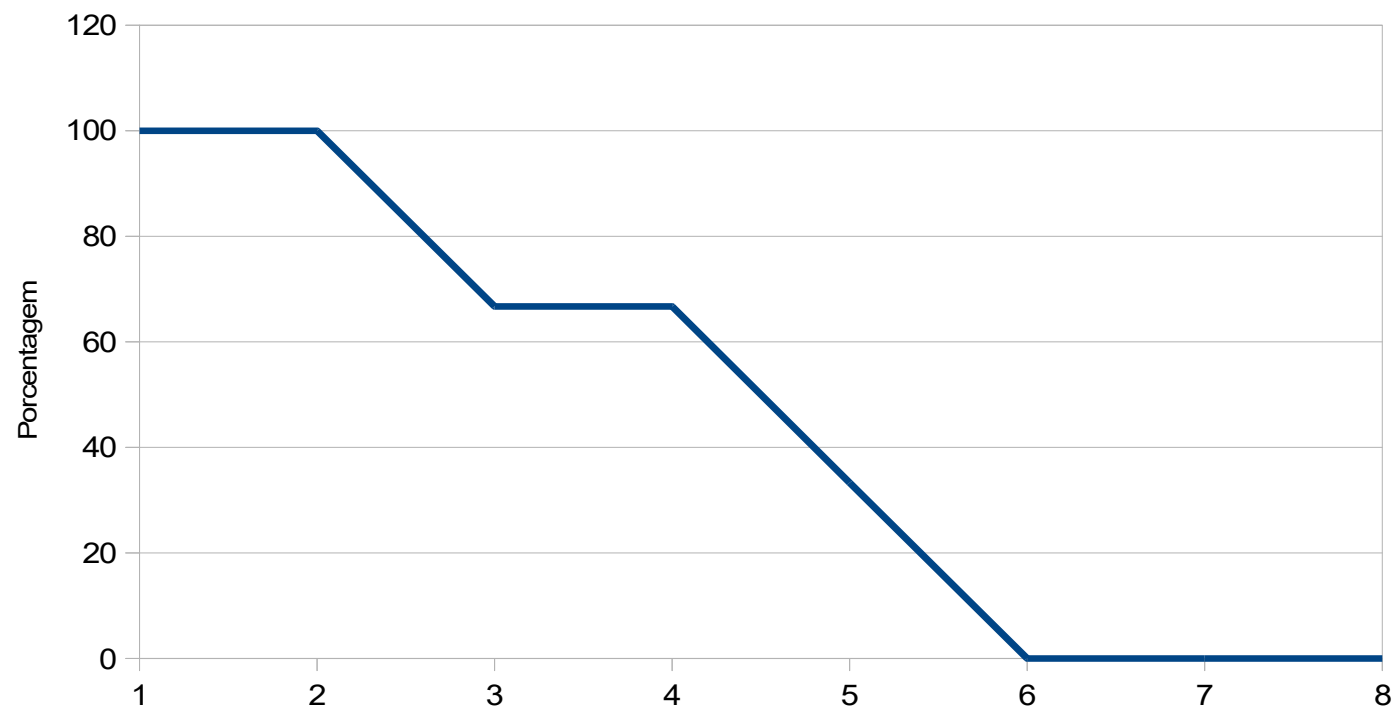

Anos 
Tabela 10 - Relação entre percentual de retirada dos fármacos antiepilépticos no último retorno e resultado comparativo da avalição neuropsicológica pré e pós-operatório.

\begin{tabular}{|c|c|c|}
\hline \multirow{2}{*}{ Casos } & Percentual de uso de FAE & $\begin{array}{c}\text { Comparação de avalição } \\
\text { neuropsicológica }\end{array}$ \\
\hline & Último retorno & \\
\hline 1 & 33,3 & - \\
\hline 2 & 100 & - \\
\hline 3 & 100 & - \\
\hline 4 & 33,3 & Mantida \\
\hline 5 & 150 & - \\
\hline 6 & 50 & - \\
\hline 7 & 66,7 & - \\
\hline 8 & 66,7 & - \\
\hline 9 & 33,3 & Mantida \\
\hline 10 & 33,3 & Melhor \\
\hline 11 & 66,7 & - \\
\hline 12 & 50 & - \\
\hline 13 & 0 & Melhor \\
\hline 14 & 0 & Melhor \\
\hline 15 & 100 & Mantida \\
\hline 16 & 50 & - \\
\hline 17 & 66,7 & Mantida \\
\hline 18 & 75 & Melhor \\
\hline 19 & 0 & Melhor \\
\hline 20 & 33,3 & Pior \\
\hline 21 & 100 & Pior \\
\hline 22 & 100 & - \\
\hline 23 & 50 & Mantida \\
\hline 24 & 100 & Mantida \\
\hline 25 & 100 & Pior \\
\hline 26 & 50 & Mantida \\
\hline 27 & 50 & Mantida \\
\hline 28 & 50 & Mantida \\
\hline 29 & 25 & Mantida \\
\hline 30 & 25 & Melhor \\
\hline 31 & 0 & - \\
\hline 32 & 50 & Melhor \\
\hline 33 & 40 & - \\
\hline 34 & 100 & Mantida \\
\hline 35 & 75 & Mantida \\
\hline 36 & 33,3 & - \\
\hline 37 & 66,7 & Mantida \\
\hline 38 & 50 & Mantida \\
\hline 39 & 40 & Mantida \\
\hline 40 & 100 & Mantida \\
\hline 41 & 66,7 & - \\
\hline 42 & 100 & Mantida \\
\hline 43 & 40 & Mantida \\
\hline 44 & 50 & Melhor \\
\hline
\end{tabular}


Em relação aos pacientes nos quais foi possível realização de comparações entre as avaliações neuropsicológicas pré e pós-operatórias e que tiveram modificação em FAE no período PO foi evidenciado que todos os pacientes com retirada completa de FAEs apresentaram melhora na avaliação neuropsicológica. Dos 19 pacientes com redução de FAEs no PO, 17 (89,47\%) apresentaram melhora ou mantiveram os resultados das avaliações neuropsicológicas. Dentre os pacientes com FAEs não alterados no PO, as avaliações foram mantidas ou piores em relação à avaliação pré-operatória, sendo que nenhum paciente com FAE mantido apresentou melhora no desempenho da avaliação. Em 15 pacientes não foi possível estabelecer a relação uma vez que não foram realizadas avaliações PO. Esses dados são demonstrados na tabela 10 . 


\section{DISCUSSÃO}

A eficácia da cirurgia de epilepsia é refletida a partir da diminuição do número de crises, bem como, da redução do uso de fármacos no PO (SCHMIDT et al., 2004; KANCHANATAWAN et al., 2014; MCLACHLAN; MAHER, 2000; SCHILLER et al., 2000). Diante dos resultados satisfatórios para o controle de crises nos pacientes submetidos a cirurgias hemisféricas no nosso centro, decidimos avaliar o manejo terapêutico desses pacientes a fim de averiguar se a cirurgia foi efetiva de tal modo que fosse possível descontinuar ou reduzir a quantidade de FAEs utilizados previamente ao procedimento.

Desta forma, este estudo avaliou crianças e adolescentes que tinham no mínimo dois anos de seguimento após cirurgia para observar a evolução terapêutica nessa fase PO. Para tanto, revisamos casos de pacientes operados até 2015, cuja clínica PO possibilitou essa análise.

Conhecidamente os pacientes com doença hemisférica apresentam epilepsia fármacoresistente com crises muito frequentes (DUCHOWNY et al., 1998; DUCHOWNY, 2004; WYLLIE et al., 1996; WYLLIE, 1998). No nosso estudo, analisando os 82 pacientes que tiveram os critérios de inclusão preenchidos, os dados corroboraram com a literatura, uma vez que $22(26,8 \%)$ dos pacientes apresentaram EME ou EPC e $52(63,5 \%)$ crises diárias antes do procedimento cirúrgico. Considerando os 44 pacientes utilizados para avaliação do manejo dos FAEs, 12 (27,27\%) apresentaram EME ou EPC e 26 (59,09\%) crises diárias antes da hemisferotomia.

A hemisferotomia é um procedimento eficaz com índice de remissão de crises variando de 52 a $86 \%$, ampliando-se para 78 a $91 \%$ quando se considera a melhora significativa das crises (pacientes com Engel I e II), o que, em se tratando de epilepsias graves, é um resultado altamente satisfatório (BASHEER et al., 2007; BULTEAU et al., 2008; CARRENO et al., 2001; CATS et al., 2007; DEVLIN et al., 2003; DI ROCCO et al., 2006; DUCHOWNY et al., 1998; FLACK et al., 2008; GONZALEZ-MARTINEZ et al., 2005; JONAS et al., 2004; KOSSOFF et al., 2003; LETTORI et al., 2008; O'BRIEN et al., 2006; PEACOCK et al., 1996; TERRA-BUSTAMANTE et al., 2007; TERRA-BUSTAMANTE et al., 2009; VINING et al., 1997) . Dessa forma, considerando a gravidade da epilepsia, o resultado da cirurgia para o grupo total de pacientes incluídos neste estudo foi considerado muito satisfatório, com 95\% (76 pacientes) de melhora de crises no segundo ano PO e 88,8\% na última avaliação clínica do paciente que foi realizada entre 2 anos a 19 anos (média de 7,30 
anos) após a cirurgia. Esses valores são impactantes relativamente a um correspondente de 74 (90,24\%) de pacientes com no mínimo crises diárias.

Contudo, diante dos dados de literatura que atribuem à hemisferotomia resultados de 52 a $86 \%$ de controle total de crises (Engel I), os resultados alcançados para este grupo de pacientes foram relativamente inferiores: $44(55 \%)$ no segundo ano e 38 (47,5\%) no último ano. Esses valores podem ser justificados pelas variáveis prognósticas implicadas com piores desfechos de controle de crises, segundo dados de literatura, a exemplo MDC, deficiência intelectual prévia, idade de início das crises e duração da epilepsia (DEVLIN et al., 2003; JONAS et al., 2004; KOSSOFF et al., 2003; VINING et al., 1997; FLACK et al., 2008; PEACOCK et al., 1996; TERRA-BUSTAMANTE et al., 2007). A MDC é considerada um fator de pior prognóstico para controle de crises, resultando em refratariedade de crises no PO (DEVLIN et al., 2003; JONAS et al., 2004; KOSSOFF et al., 2003; VINING et al., 1997) . Os estudos com crianças menores, com menor tempo de duração de epilepsia, demonstram melhores resultados no controle de crises (GONZALEZ-MARTINEZ et al., 2005; JONAS et al., 2004; LETTORI et al., 2008; KOSSOFF et al., 2003). Alguns autores discutem que o fator idade não influencia nos resultados cirúrgicos quanto ao controle de crises, mas influem no desenvolvimento e na habilidade cognitiva (DUNKLEY et al., 2011; WYLLIE, 1998; WYLLIE et al., 1998) .

A hipótese deste estudo foi observar se após a realização da hemisferotomia foi possível a redução ou a retirada de FAEs. Inferimos que a condição premente para se considerar redução de FAEs no PO seja o controle total de crises. Isso posto, foram selecionados para a avaliação de manejo de FAEs apenas aqueles pacientes que apresentavam ENGEL I no segundo ano PO, isto é, 44 pacientes. Não há, na literatura, uma definição clara sobre o tempo ideal para considerar que o paciente pós hemisferotomia esteja livre de crises e, por isso, possa ter seus fármacos manejados e retirados. Estes intervalos de tempo são determinados pela experiência de cada serviço, mas Berg e colaboradores, em um estudo com epileptólogos demonstraram que os profissionais consideram que os pacientes devem permanecer com FAEs por mais de dois anos antes de considerar a descontinuação (BERG et al, 2006). Hoppe, em 2006, descreveu que a maioria dos casos de recorrência ocorreram nos dois primeiros anos após cirurgia (HOPPE et al., 2006).

Os dados verificados no nosso estudo, permitiram que fosse realizada apenas uma análise descritiva, uma vez que esse estudo apresentou limitações estatísticas dada à casuística seleta de pacientes livres de FAEs, impossibilitando, portanto, análises estatísticas. 
Para visualizar o manejo dos FAES ao longo do PO, foram estabelecidos cortes de 1,2,5,10 anos, contemplando períodos de curto e longo prazos. Esses valores se mantêm de acordo com a literatura, quando se observa uma recorrência de crises em longo prazo de observação (JONAS et al., 2004; TELLEZ-ZENTENO et al., 2005) . Devemos considerar, contudo, um viés possível nesses valores, uma vez que os pacientes são procedentes de outras regiões, invariavelmente distantes do centro, e tendem a manter a adesão ao tratamento quando descompensam de crises no PO. Pacientes que se encontram com bom controle de crises no PO tendem a manter seguimento em suas cidades ou estados de origem. Na literatura discute-se esse possível viés, nas avaliações tardias, de que pacientes que permanecem com crises tenderiam a manter o seguimento com maior adesão do que aqueles com remissão, subestimando o percentual de remissão nas avaliações de longo prazo (TELLEZ-ZENTENO et al., 2005).

Tratando-se de cirurgia hemisférica, cujos casos são mais associados a epilepsia na faixa pediátrica, comumente cursando com crises de início precoce, as faixas etárias de início de crise entre zero e 159 meses (média de 42,57士42,12) estiveram de acordo com as demais séries de hemisferotomia que demonstraram variação entre zero a 136 meses (DEVLIN et al., 2003; KOSSOFF et al., 2003; JEONG et al., 2017).

A idade das crianças no momento da cirurgia variou de 10 meses a 18,4 anos, sendo que a maioria dos pacientes foi operada nas faixas etárias de lactentes/pré-escolar e escolar $(72,72 \%)$, o que tem relação com a etiologia que atinge faixas díspares, como MDC $(38,64 \%)$ mais associada a epilepsia em lactente, encefalite de Rasmussen em crianças em faixa etária escolar (31,82\%). Esses dados estão em conformidade com outras séries que incluem diversas patologias (BASHEER et al., 2007; DEVLIN et al., 2003; KOSSOFF et al., 2003; LETTORI et al., 2008; PEACOCK et al., 1996; VINING et al., 1997) . Contudo, há de se ponderar que a cirurgia ainda é a última alternativa de tratamento, principalmente considerando as dificuldades de avaliação e acesso a centros de referência de cirurgia de epilepsia no nosso país, devido à restrição financeira e procedência de outros estados que não São Paulo, localização do nosso centro - 77,3 \% dos pacientes são procedentes de outros estados. Esses dados podem ter colaborado para que a idade na cirurgia fosse na média de 7 anos, divergindo da literatura em que os dados indicam cirurgia em idade mais precoce (DUCHOWNY et al., 1998; DUNKLEY et al., 2011; HARVEY et al., 2008; WYLLIE et al., 1996). Ademais, essa idade média de 7 anos apresenta disparidade das médias de idade de início de crises $(3,54$ anos) e de duração da epilepsia (62,6 meses), sugerindo que as dificuldades para o acesso e para realização de cirurgia de epilepsia em crianças no Brasil postergam a possibilidade desta 
alternativa de tratamento. A duração da epilepsia na nossa casuística variou de 1 mês a mais de 151 meses, com média de 62,6 meses. Nas séries de Devlin et al., 2003, Kossof et al., 2003, e Jonas et al., 2004, a duração da epilepsia variou de 43 a 47 meses (DEVLIN et al., 2003; JONAS et al., 2004; KOSSOFF et al., 2003) . Para alguns autores, a duração da epilepsia não é fator prognóstico considerado significativo para controle de crises, sendo esse, portanto, um dado que não justificaria a dificuldade de retirada ou redução de fármacos no PO da nossa amostra (DUCHOWNY et al., 1998; DUNKLEY et al., 2011; WYLLIE et al., 1998) . Em alguns estudos prévios demonstrou-se uma associação negativa entre a duração da epilepsia e exame neuropsicológico. Jeong et al., em seu estudo coorte não conseguiu determinar a relação entre o maior tempo de duração de epilepsia e a piora em testes neuropsicológicos, entretanto sua casuística era pequena. No nosso trabalho essa relação não foi estabelecida, uma vez que os objetivos não correspondiam a tal análise (JEONG et al., 2017).

No que se refere ao sexo, nossa amostra, com pacientes incluídos no estudo, evidenciou equivalência entre meninos e meninas, diferenciando das series de literatura, em que há predomínio do sexo feminino (JEONG et al., 2017; HOPE et al., 2006; LHACHWANI et al., 2007; KOSSOF et al., 2003; PULSIFER et al., 2004; BOSHWSEN et al., 2009).

A hemisferotomia é um procedimento complexo que, embora seguro, é passível de complicações e dificuldades técnicas do procedimento em si, particularmente nos casos de MDC, HME, quando há maior frequência de variação anatômica estrutural e vascular (BASHEER et al., 2007; DEVLIN et al., 2003; DI ROCCO et al., 2006; FLACK et al., 2008; JONAS et al., 2004; PEACOCK et al., 1996) . Por essa razão, por vezes a cirurgia não atinge o objetivo da plena desconexão e há necessidade de reabordagem para alcançar o resultado esperado para o controle de crises. Tivemos, na série, três casos com necessidade de reabordagem: uma condição com diagnóstico de encefalite de Rasmussen e dois casos com MDC, sendo que um deles era HME e com idade muito precoce no momento da cirurgia. Para estes pacientes, foi considerada a segunda abordagem cirúrgica como base para avaliação do manejo de FAEs. Os três pacientes ficaram livres de crises após a reabordagem, sendo um deles um dos pacientes foi possível retirada completa de FAE.

Em 56,82\% dos pacientes a cirurgia foi realizada do lado esquerdo, o que difere de alguns dados encontrados em literatura que demonstram maioria das cirurgias do lado direito (HOPE et al., 2006; JEONG et al., 2017; KOSSOF, 2003; PULSIFER et al., 2004; DEVLIN et al., 2003; DORFER et al., 2015).

No que tange à etiologia, utilizamos classificação já adotada por alguns autores (BASHEER et al., 2007; DEVLIN et al., 2003; KOSSOFF et al., 2003; LETTORI et al., 2008; 
PEACOCK et al., 1996; VINING et al., 1997) e encontramos uma amostra constituída de 17 (38,64\%) casos de MDC, dos quais 6 apresentavam HME; 13 (29,55\%) pacientes com patologias adquiridas e $14(31,82 \%)$ com patologias progressivas. Nossa casuística difere de dados encontrados por outros autores que demonstraram amostras constituídas por distribuição proporcional entre lesões adquiridas e doenças progressivas, constituindo cerca de 50\% das amostras e os outros 50\% MDC ( DEVLIN et al., 2003; JONAS et al., 2004; PEACOCK et al., 1996) .

A hemisferotomia é uma terapia indicada para pacientes fármaco-resistentes, além de ser uma possibilidade para redução de fármacos em pacientes em uso de politerapia. Em nossa amostra, o número de fármacos utilizados pelos pacientes variou de 2 a 5 , o que está em conformidade com dados encontrados na literatura (JEONG et al., 2017; KOSSOF, 2003). Na revisão de BOSHUISEN e colaboradores, os pacientes usavam de zero a cinco fármacos (média de 1,8) em fase pré-operatória imediata (BOSHUISEN et al.,2012).

Não há um consenso sobre quanto tempo PO é necessário aguardar para iniciar a retirada de FAEs. Foram encontradas variações de início de retirada entre 2 meses e 126 meses (12,6 anos). No entanto, o intervalo maior que seis meses é defendido pela maioria dos autores, ficando a critério da experiência de cada serviço a determinação sobre o tempo PO para iniciar retirada das medicações (LHACHWANI et al., 2007; KOSSOF et al., 2003; KERLING et al., 2009; TELLEZ-ZENTENO et al., 2012; BOSHUISEN et al., 2012; HOPE et al., 2006). Assim como na literatura, no nosso serviço não é estabelecida uma data ideal para iniciar retirada e/ou redução de fármacos. A redução e retirada são realizadas em indivíduos que estão livres de crises, sendo que a variação de tempo entre a cirurgia e diminuição do primeiro fármaco foi de 1 dia a 4 anos e o tempo de retirada do primeiro fármaco chegou a até 96 meses.

A recorrência das crises, independente da causa, nos pacientes operados no nosso centro, ocorreu entre 0,16 a 12 anos após a cirurgia, com uma média de 4,45 anos, sendo a recorrência relacionada à retirada de fármacos ocorrendo entre 0,25 a 9 anos PO. A literatura mostra dados variáveis. Alguns autores defendem que a recorrência em geral ocorre em curto espaço de tempo após a cirurgia (HOPE et al., 2006) enquanto outros demonstram que a recorrência é maior com o passar dos anos (BELL et al., 2011).

Estudos que avaliaram a recorrência de crise epiléptica após retirada de fármacos demonstraram uma variação significativa, com 9 a $80 \%$ dos pacientes operados apresentando recorrência de crises após retirada ou redução de fármacos. Na nossa série, encontramos uma taxa de recorrência de 52,27\% dos pacientes avaliados após 2 anos de seguimento. Desses, 34\% 
recorreram crises após redução de fármacos e $25 \%$ após retirada de algum fármaco usado previamente. Os estudos que relacionam a retirada ou redução de fármacos demonstram resultados controversos, enquanto Kerling et al. e Berg et al. demonstraram que a recorrência de crise era maior em grupos controle nos quais não foram alterados os fármacos, Lhachwani, et al. demonstraram maior recorrência no grupo cujos fármacos foram reduzidos ou retirados (JEONG et al., 2017; SCHMIDT et al., 2004; HOPE et al., 2006; TELLEZ-ZENTENO et al., 2012; LHACHWANI et al., 2005; KOSSOF, 2003; PULSIFER et al., 2004; KERLING et al., 2009; BOSHUISEN et al., 2009).

Eventos adversos, altas doses dos FAEs, com impacto no estado comportamental, cognitivo e de desenvolvimento na criança podem justificar a retirada ou redução mais precoce dos FAEs. O intervalo entre a cirurgia e a retirada de todos os fármacos, naqueles pacientes nos quais tal prática foi possível, foi de 6,84 a 9 anos. Na literatura, em séries cujos pacientes eram adultos, o tempo de retirada variou de 1 a 5 anos, enquanto séries pediátricas demosntraram variação entre 0 a 6,3 anos para iniciar retirada de FAEs (SCHMIDT et al., 2004; HOPE et al., 2006; KERLING et al., 2009; BERG et al., 2004). A suspensão da medicação em pacientes sem crises no PO no nosso serviço foi bastante restrita. Tal fato pode ser atribuído a diversidade e dificuldade geográfica, o que impossibilita retornos precoces e frequentes que encorajassem a família e a equipe médica a realizar a retirada de FAEs. Além disso, o adiamento da prática cirúrgica fez com que a duração da epilepsia fosse prolongada, resultando em casos de maior gravidade com número elevado de EME/EPC e crises diárias, o que não motivava as famílias para que fossem retirados FAEs, devido ao risco de recidiva que poderia associado a suspensão. A organização das redes de saúde no Brasil não favorece o contato direto dos médicos de diferentes regiões, o que tornaria esse processo de desmame da medicação mais viável, seguro e natural. O intervalo de consultas de pacientes controlados de crises e provenientes de outros estados costuma ser anual, somando as dificuldades no processo.

Os FAEs também atuam no nível cognitivo, influenciando no desenvolvimento e no comportamento dos indivíduos. Esse é um grande argumento utilizado para justificar a retirada de FAEs precocemente na infância (BOSHUISEN et al., 2015).

Diante dessas informações, verificamos que o nosso serviço é mais conservador no desmame de medicações no PO. Na nossa casuística, apenas quatro pacientes permaneceram livre de crises e sem uso de fármacos antiepiléticos no momento do último retorno antes da realização deste estudo, o que é um baixo índice em relação ao que é encontrado em literatura, cujos resultados variam em até 80 a 90\% (HOPE et al., 2006; KOSSOF, 2003). Quatro 
$(9,09 \%)$ pacientes, que tiveram fármacos suspensos e recorrência de crises, retornaram uso de fármacos prévios e 3 deles obtiveram controle de crises. Além disso, 13 pacientes precisaram receber novos fármacos e desses, apenas quatro obtiveram sucesso no controle das crises. $\mathrm{Na}$ literatura, os dados são mais positivos, com taxa de sucesso em controle de crises variando de 63,6\% a 97\% após reintrodução de fármacos (HOPE et al., 2006; SCHMIDT et al., 2004). Essa discordância não pode ser considerada absoluta, uma vez que a retirada de FAEs no nosso centro foi muito restrita, bem como, foi limitada a redução de medicações em curto prazo. Essa variação entre as séries pode ser explicada pelo número muito pequeno da nossa amostra.

Assim, nossa baixa taxa de sucesso de retirada de fármacos em pacientes livres de crises pode estar relacionada com a dificuldade de manejo de fármacos nesses pacientes cujas cidades de origem são distantes e o acompanhamento pós cirúrgico ocorrem com intervalo de tempo mais espaçado. Além disso, alguns pacientes podem apresentar crises não epilépticas após cirurgia de epilepsia bem-sucedida. Castro, em 2007, em uma revisão sobre crises não epilépticas e cirurgia na epilepsia, relatou que as crises não epilépticas são uma condição reconhecida há muito tempo e, em muitos casos, não está claro se tais crises já estavam presentes antes da cirurgia (e o diagnóstico não foi realizado) ou se representam uma ocorrência nova no PO (CASTRO, 2007). Esta condição também pode ser um fator relacionado com a dificuldade de retirada de FAEs. Dados relacionados a presença de crise não epiléptica não estavam disponíveis em prontuários para análise desse quesito.

Apesar dos resultados demonstrarem a baixa taxa de retirada de fármacos no PO, verificamos que a porcentagem de fármacos utilizados pelos pacientes no PO apresentou uma queda expressiva. A percentagem de uso de fármacos, que antes da cirurgia foi adotada como $100 \%$, apresentou queda para $81,7 \%$ após 6 meses PO, 83,5\% após um ano PO, 72,4\% em dois anos $\mathrm{PO}, 55,2 \%$ aos cinco anos $\mathrm{PO}, 44,4 \%$ após 10 anos $\mathrm{PO}$ e à última avaliação, 58,4\%. Esses resultados são expressivos se consideramos o percentual em cima do número absoluto de FAEs utilizados previamente ao procedimento cirúrgico como demonstrado na tabela 8 . Esta redução foi possível devido à melhora nas crises epilépticas dos pacientes, confirmando a eficácia da hemisferotomia. A descontinuação de FAEs, além do controle de crises, é uma das razões pelas quais os pacientes são submetidos à cirurgia de epilepsia, mas pouco é conhecido sobre o risco de recorrência de crises. O tempo para iniciar retirada de FAEs não é em estabelecido em literatura, porém os estudos demonstram que a descontinuação do FAE após cirurgia de epilepsia bem-sucedida não é associada a um risco de recorrência de crises. Se a descontinuação dos FAEs é realizada após período de 6 meses, espera-se que os pacientes 
permaneçam livres de crises. Além disso, manutenção de FAE a longo prazo não está indicada em crianças com ressecção completa da zona epileptogênica, visto os efeitos secundários das medicações, como efeitos adversos e influência no desenvolvimento cognitivo (BOSHUISEN et al., 2009; KERLING et al., 2009). Um fator notado é que, com o passar dos anos, as famílias sentem-se mais seguras em relação a retirada de FAE, a epilepsia vai ficando no passado mais remoto e vem sendo mais natural o processo. Téllez-Zenteno, em sua publicação no ano de 2012, ao avaliar os fatores considerados para descontinuação de FAE após cirurgia de epilepsia, demonstrou que o desejo do paciente e da família em retirar os FAEs são considerados para prosseguir em tal prática (TÉLLEZ-ZENTENO et al., 2012).

É sabido que a hemisferotomia além da eficácia sobre o controle das crises tem impacto positivo sobre o desenvolvimento motor e cognitivo, uma vez que mantem estáveis índices como coeficiente de desenvolvimento e coeficiente de inteligência, o que já é considerado por si mesmo sem ganho nas encefalopatias epilépticas, quando o esperado é involuir ou desacelerar o desenvolvimento (BERG, 2010). Os dados da literatura evidenciaram que o impacto da cirurgia não é apenas no controle de crises, mas também na qualidade de vida e desenvolvimento dos pacientes (SPENCER, 1996). Os estudos indicam que a diminuição ou fim das crises epilépticas está associada a melhor desenvolvimento intelectual no PO. De forma geral, demonstram padrão de melhora ou, no mínimo, estabilidade nas avaliações cognitivas PO quando comparadas as avalições pré-operatórias, na maioria dos pacientes com cirurgia de epilepsia bem sucedida (PULSIFER et al., 2004; DEVLIN et al., 2003; DI ROCCO et al., 2006; JONAS et al., 2004; LETTORI et al., 2008). Com nossa amostra não foi diferente, sendo que 32 (44\%) dos pacientes realizaram avaliação neuropsicológica no PO. Destes, 18 (56,2\%) mantiveram a eficiência cognitiva demonstrada no momento pré-operatório e 7 (22\%) apresentaram melhora na eficiência cognitiva. Os testes são de difícil aplicação para crianças comprometidas cognitivamente, bem como a disponibilidade dos profissionais capacitados para essa avaliação nos períodos do atendimento cirúrgico neste centro e a procedência dos pacientes de outros estados do país são fatores que, em conjunto, não possibilitaram que essa análise neuropsicológica fosse realizada em 100\% da nossa casuística. O desfecho Engel I pode ter sido implicado com esse impacto positivo sobre o desenvolvimento, uma vez que este é considerado por outros autores como fator prognóstico positivo para controle de crises (ALTHAUSEN et al., 2012). Observamos que em pacientes nos quais a cirurgia foi bem-sucedida houve ainda a possibilidade de redução de FAEs, fato que também corrobora com melhora ou manutenção nos níveis de eficiência intelectual das avaliações neuropsicológicas, visto que os FAEs atuam no nível cognitivo e 
influenciam no desenvolvimento e no comportamento dos indivíduos (BOSHUISEN et al., 2015. No nosso estudo, todos os pacientes com retirada completa de FAEs apresentaram melhora na avaliação neuropsicológica, $89,47 \%$ dos pacientes com redução de FAE no PO apresentaram melhora ou mantiveram os resultados das avaliações neuropsicológicas e dentre os pacientes com FAEs mantidas no PO, as avaliações foram mantidas ou piores em relação à avaliação pré-operatória, sendo que nenhum paciente com FAE mantido apresentou melhora no desempenho da avaliação. 


\section{CONCLUSÕES}

A hemisferotomia, para o controle de crises farmacologicamente refratárias, gera uma expectativa para pacientes e familiares no que tange à descontinuação de uso de medicação. A cirurgia bem sucedida permite redução ou retirada de fármacos minimizando os efeitos nocivos ao desenvolvimento neuropsicomotor do paciente. Na nossa série a retirada completa de FAE não foi expressiva, no entanto, a redução de FAE foi relevante em números absolutos e percentuais. A eficácia da hemisferotomia para controle e redução de crises foi verificada nas avaliações PO de curto e longo prazos. Observou-se recorrência de crises em longo prazo de seguimento, mas é importante considerar o viés da procedência dos pacientes.

Em relação ao manejo dos FAEs no PO, em curto e longo prazos, foi observada redução em números absoluto e percentual, com redução para 81,7\% após 6 meses PO, e queda gradual da percentagem de redução de FAE chegando a menos que 50\% após 10 anos de PO.Não houve consenso no que tange ao tempo mínimo para iniciar a retirada de FAE nos pacientes livre de crises após hemisferotomia. O início da redução foi precoce em alguns casos, mas, verificou-se uma variação de tempo bastante ampla para iniciar a redução $(0,002$ a 4 anos). Além disso, a retirada completa, em pacientes nos quais foi possível, foi tardia (média 8 anos). O serviço não possui protocolo definido para redução ou retirada de FAE no PO, sendo o manejo baseado nas evoluções clínicas, seguimento do paciente e experiência da equipe.

A recorrência de crise epiléptica após retirada de fármacos demonstrou uma variação relevante e resultados controversos, existindo recorrência de crises com manutenção ou retirada de fármacos, sendo necessários mais estudos para determinar este dado.

A hemisferotomia, além da eficácia sobre o controle das crises, tem impacto positivo sobre o desenvolvimento e função cognitiva, mantendo estáveis, ou melhorando, índices de coeficientes de desenvolvimento e de inteligência.

Os bons desfechos cognitivos e de desenvolvimento relacionaram-se com a redução e retirada de FAEs nos pacientes que ficaram livres de crises após hemisferotomia, devendo ser considerado o desfecho Engel I como uma variável que pode ter implicação com esse impacto positivo, o que foi um fator de viés no estudo. 


\section{REFERÊNCIAS}

ALTHAUSEN, A. et al. Long-term outcome of hemispheric surgery at different ages in 61 epilepsy patients. Journal of Neurololy, Neurosurgery and Psychiatry, v. 84, p. 529-536, 2013.

AMARAL, L.C. et al. Tratamento cirúrgico da epilepsia refratária: análise de 34 casos atendidos no Hospital das Clínicas da UFMG. Arquivos Brasileiros de Neurocirurgia, v. 33, n. 2, p. 112-114, 2014.

ANNEGERS, J.F.; HAUSER W.A.; ELVEBACK LR. Remission of seizures and relapse in patients with epilepsy. Epilepsia, v. 20, p.729-739, 1979.

ARTS, W.F. et al. Course and prognosis of childhood epilepsy: 5-year follow-up of the Dutch study of epilepsy in childhood. Brain, v. 127, p. 1774-1784, 2004.

BAILEY, P.; GIBBS, F.A. The surgical treatment of psychomotor epilepsy. Journal of the American Medical Association, v. 145, n. 06, p. 365-370, 1951.

BARKOVICH, R.I. et al. Classification system for malformations of cortical development. Neurology, v.57, n. 12, p. 2168-2178, 2001.

BASHEER, S.N. et al. Hemispheric surgery in children with refractory epilepsy: seizure outcome, complications, and adaptive function. Epilepsia, v. 48, p. 133-140, 2007.

BAUMGARTNER, J.E. et al. Technical descriptions of four hemispherectomy approaches: from the pediatric epilepsy surgery meeting at Gothenburg 2014. Epilepsia, v. 58, p. 46-55, 2017.

BEIER, A.D.; RUTKA, J.T. Hemispherectomy: historical review and recent technical advances. Neurosurgical focus, v.34, n.6, E11, 2013.

BELL, T.J. et al. The long-term outcome of adult epilepsy surgery, patterns of seizure remissiom and relapse: a cohort study. Lancet, v. 378, p. 1388-1395, 2011.

BERG, A.T., SHINNAR, S. Relapse following discontinuation of anti-epileptic drugs: metaanalysis. Neurology, v.44, p.601-608, 1994.

BERG, A.T. et al. Stopping antiepileptic drugs after successful surgery: what do we know? And what do we stil need to learn? Epilepsia, v. 45, n. 2, p. 101-102, 2004.

BERG, et al. How long does it take for epilepsy to become intractable? A prospective investigation. Annals of Neurology, v. 60, p.73-79, 2006.

BERG, A.T. et al. Stopping antiepileptic drugs after epilepsy surgery: a survey of US epilepsy center neurologists. Epilepsy and Behavior, v. 10, n. 2, p. 219-222, 2007.

BERG, A.T. et al. Revised terminology and concepts for organization of seizures and epilepsies: report of the ILAE Commission on Classification and Terminology. Epilepsia, v. 51, p. 676-685, 2010. 
BORGES, M.A. et al. Urban prevalence of epilepsy: populational study in São José do Rio Preto, a medium-sized city in Brazil. Arquivos de Neuro-psiquiatria, v. 62, n. 2, p.199-204, 2004.

BOSHUISEN, K. et al. Medication policy after epilepsy surgery. Pediatric Neurology, v. 41, p. 332-338, 2009.

BOSHWSEN, K. et al. Timing of antiepileptic drug withdrawal and long-term seizure outcome after paediatric epilepsy surgery (TimeToStop): a retrospective observational study. The Lancet Neurology, v. 11, p. 784-791, 2012.

BULTEAU et al. Long-term outcome after hemispheric disconnection. Neurochirurgie, v. 54, p. 358-361, 2008.

CAMFIELD, P.; CAMFIELD, C. The frequency of intractable seizures after stopping AEDs in seizure-free children with epilepsy. Neurology, v. 64, p. 973-975, 2005.

CARRENO et al. Seizure outcome after functional hemispherectomy for malformations of cortical development. Neurology, v. 57, p. 331-333, 2001.

CASTRO, L.H.M. Epilepsy surgery in patients with coexisting psychogenic nonepileptic seizures: Diagnosis and treatment. Journal of Epilepsy Clinical Neurophysiology, v. 13, n. 4, p. 36-38, 2007.

ÇATALTEPE, O. Hemispherectomy and hemispherotomy techniques in pediatric epilepsy surgery: an overview. Pediatric Epilepsy Surgery, p. 205-214, 2010.

CATS, E.A. et al. Seizure freedom after functional hemispherectomy and a possible role for the insular cortex: the Dutch experience. Journal of Neurosurgery: Pediatrics, v. 107, p. 275-280, 2007.

COSTA, J.C.; PORTELA, E.J. Tratamento Cirúrgico das Epilepsias na Criança. Journal of Epilepsy Clinical Neurophysiology, v. 12, p. 32-43, 2006.

CROSS, J.H. Epilepsy surgery in childhood. Epilepsia, v.43, p. 65-70, 2002.

CRUZ, M.B.Z. WISC III: Escala de inteligência Wechsler para crianças: Manual. Avaliação Psicológica, v. 4, n. 2, p. 199-201, 2005.

DEVLIN, A.M. et al. Clinical outcomes of hemispherectomy for epilepsy in childhood and adolescence. Brain, v. 126, p. 556-566, 2003.

DI ROCCO, C. et al. Hemimegalencephaly: clinical implications and surgical treatment. Child's Nervous System, v. 22, p 852-866, 2006.

DODRILL, C.B. et al. An objective method for the assessment of psychological and social problems among epileptics. Epilepsia, v.21, p. 123-135, 1980. 
DOOLEY, J.M. et al. Discontinuation of anticonvulsant therapy in children free of seizures for 1 year. Neurology, v.46, p. 969-974, 1996.

DORFER, c. et al. Functional hemispherectomy for catastrophic epilepsy in very young infants: technical considerations and complication avoidance. Child's Nervous System, v. 31, p. 2103-2109, 2015.

DUARTE, C.S.; BORDIN, I. AS. Instrumentos de avaliação. Revista Brasileira de Psiquiatria, v. 22, p. 55-58, 2000.

DUCHOWNY, M. et al. Epilepsy surgery in the first three years of life. Epilepsia, v. 39, p. 737-743, 1998.

DUCHOWNY, M. Hemispherectomy for epilepsy: when is one half better than two? Neurology, v. 62, p. 1664-1665, 2004.

DUNKLEY, C. et al. Epilepsy surgery in children under 3 years. Epilepsy Research, v.93, p. 96-106, 2011.

ENGEL, J. Jr. Surgery for seizures. The New England Journal of Medicine, v. 334, n. 10, p. 647-652, 1996.

ENGEL, J. Jr. et al. Practice parameter: temporal lobe and localized neocortical resections for epilepsy. Neurology, v.60, p. 538-547, 2003.

EPILEPSY FOUNDATION. Epilepsy and seizure statistics. Disponível em: www.epilepsyfoundation.org/about/statistics.cfm.

FEINDEL, W. et al. Epilepsy Surgery: Historical Highlights 1909-2009. Epilepsia, v. 50, p. 131-151, 2009.

FLACK, S. et al. Cerebral hemispherectomy in infants and young children. Paediatric Anaesthesia, v. 18, p. 967-973, 2008.

GONZALEZ-MARTINEZ, J.A. et al. Hemispherectomy for catastrophic epilepsy in infants. Epilepsia, v. 46, p. 1518-1525, 2005.

HARVEY, A.S. et al. Defining the spectrum of international practice in pediatric epilepsy surgery patients. Epilepsia, v. 49, p. 146-155, 2008.

HAUSER, W.A. et al. Descriptive epidemiology of epilepsy: Contributions of population based studies from Rochester, Minnesota. Mayo Clinic Proceedings, v.71, p.576-586, 1996.

HOPE, C. et al. Discontinuation of Anticonvulsant Medication after Epilepsy. Surgery in Children. Epilepsia, v. 47, n. 3, p.580-583, 2006.

HORSLEY, V. British Medical Association. The British Medical Journal, v. 2, p. 670-677, 1886. 
IGNELZI, R.J.; BUCY, P.C. Cerebral hemidecortication in the treatment of infantile cerebral hemiatrophy. The Journal of nervous and mental disease, v. 147, p. 14-30, 1968.

JEONG, A. et al. Hemispherotomy in children with electrical status epilepticus of sleep. Journal of Neurosurgery Pediatrics, v.19, p. 56-62, 2017.

JONAS, R. et al. Cerebral hemispherectomy: hospital course, seizure, developmental, language, and motor outcomes. Neurology, v. 62, p. 1712-1721, 2004.

KANCHANATAWAN, B. et al. Clinical predictors of 2-year outcome of resective epilepsy surgery in adults with refractory epilepsy: a cohort study. BMJ Open, v.4:e004852, 2014.

KERLING, F. et al. Drug withdrawal after successful epilepsy surgery: How safe is it? Epilepsy and Behavior, v.15, p.476-480, 2009.

KOSSOF, E.H. Hemispherectomy for intractable unihemispheric epilepsy etiology and outcome. Neurology, v. 61, p. 887-890, 2003.

KOUBEISSI, M.Z. et al. Hemispherectomy - associated complications from the Kid's Inpatient Database. Epilepsy Research, v. 87, p. 47-53, 2009.

KRYNAUW, R.A. et al. Infantile hemiplegia treated by removing one cerebral hemisphere. Journal of Neurololy, Neurosurgery and Psychiatry, v.13, p.243-267, 1950.

KULKARNI, S.D. et al. Hemispherotomy in an infant with hemimegalencephaly. Journal of Pediatric Neurosciences, v. 10, p. 188-192, 2015.

LETTORI, D. et al. Early hemispherectomy in catastrophic epilepsy: a neuro-cognitive and epileptic long-term follow-up. Seizure, v.17, p. 49-63, 2008.

LEW, S.M. Hemispherectomy in the treatment of seizures: a review. Translational Pediatrics, v. 3, n. 3, p. 208-217, 2014.

LHACHWANI, D.K.et al. Pediatric epilepsy surgery: lessons and challenges. Seminars Pediatric Neurology, v. 12, p. 114-118, 2005.

LIMBRICK, D.D. et al. Hemispherotomy: efficacy and analysis of seizure recurrence. Journal of Neurosurgery Pediatrics, v.4, p. 323-332, 2009.

LOWENSTEIN, D.H. et al. Seizures and epilepsy. In: Fauci AS, asper DL, Longo DL, eds. Harrison's Principles of Internal Medicine, 17th ed. Section 2: Diseases of the Central Nervous System. New York: McGraw-Hill, 2008. p. 2498-2512.

MCLACHLAN E MAHER. Management of antiepileptic drugs following epilepsy surgery: a review. Journal Neurological Sciences, v. 1, p. 106-110, 2010.

NATIONAL INSTITUTE OF NEUROLOGICAL DISORDERS AND STROKE. Seizures and Epilepsy: Hope through research. Disponível em: www.ninds.nih.gov/disorders/epilepsy/detail_epilepsy.htm. Acesso em 06 abr. 2018. 
OBEID, M. et al. Approach to pediatric epilepsy surgery: State of the art, Part II: Approach to specific epilepsy syndromes and etiologies. European Journal of Paediatric Neurology, v.13, p. 115-127, 2009a.

O'BRIEN, et al. Anatomical hemispherectomy for intractable seizures: excellent seizure control, low morbidity and no superficial cerebral haemosiderosis. Child's Nervous System, v. 22, p. 489-498, 2006.

PASSOS, G. Epilepsy Surgery - History and Evolution. Arquivos Brasileiros de Neurocirurgia, June. 2016. Disponível em: https://www.thiemeconnect.com/products/ejournals/issue/eFirst/10.1055/s-00028832. DOI: $10.1055 / \mathrm{s}-0037-1604029$.

PEACOCK, W.J. et al. Hemispherectomy for intractable seizures in children: a report of 58 cases. Child's Nervous System, v. 12, p. 376-384, 1996.

PULSIFER, M.B. et al. The cognitive outcome of hemispherectomy in 71 children. Epilepsia, v. 45, p. 243-254, 2004.

RASMUSSEN T. Hemispherectomy for seizures revisited. The Canadian Journal Neurological Sciences, v.10, p. 71-79, 1983.

RHODES, M.E. et al. Ketogenic diet decreases circulating concentrations of neuroactive steroids of female rats. Epilepsy e Behavior, v. 7, p.231-239, 2005.

SCHILLER, Y. et al. Discontinuation of antiepileptic drugs after successful epilepsy surgery. Neurology, v.54, p. 346-349, 2000.

SCHMIDT, D.; LOSCHER, W. How effective is surgery to cure seizures in drug-resistant temporal lobe epilepsy? Epilepsy Research, v. 56, p. 85-91, 2003.

SCHMIDT, D. et al. Seizure recurrence after planned discontinuation of antiepileptic drugs in seizure-free patients after epilepsy surgery: a review of current clinical experience. Epilepsia, v. 45, p.179-186, 2004.

SHINNAR, S. et al. Predictors of multiple seizures in a cohort of children prospectively followed from the time of their first unprovoked seizure. Annals Neurology, v. 48, p.140-147, 2000 .

SILLANPAA, M. Children with epilepsy as adults: outcome after 30 years of follow-up. Acta Paediatrica Scandinavica. Supplement, v. 368, p. 1-78, 1990.

SPENCER, S.S. Long-term outcome after epilepsy surgery. Epilepsia, v. 37, n. 9, p. 807-813, 1996.

TELLEZ-ZENTENO, J.F. et al. Long-term seizure outcomes following epilepsy surgery: a systematic review and meta-analysis. Brain, v.128, p. 1188-1198, 2005.

TELLEZ-ZENTENO, J.F. et al. Long-term outcomes in epilepsy surgery: antiepileptic drugs, mortality, cognitive and psychosocial aspects. Brain, v. 130, p.334-345, 2007. 
TELLEZ-ZENTENO, J.F. et al. Discontinuation of antiepileptic drugs after successful epilepsy surgery. A Canadian survey. Epilepsy Research, v.102, p. 23-33, 2012.

TENNISON, M. et al. Discontinuing antiepileptic drugs in children with epilepsy: a comparison of a six-week and a nine-month taper period. New England Journal of Medicine, v.330, p.1407-1410, 1994.

TERRA-BUSTAMANTE, V.C. et al. Outcome of hemispheric surgeries for refractory epilepsy in pediatric patients. Child's Nervous System, v. 23, p. 321-326, 2007.

TERRA-BUSTAMANTE, V.C. et al. Rasmussen encephalitis: long-term outcome after surgery. Child's Nervous System, v. 25, p. 583-589, 2009.

VADERA, S. et al. Reoperative hemispherectomy for intractable epilepsy: a report of 36 patients. Neurosurgery, v. 71, p. 388-392, 2012.

VILLEMURE, J.G. Disconnective hemispherectomy for hemispheric dysplasia.

Epileptic Disorders: international epilepsy jornal with videotape, v. 5, p. S 125-S 130, 2003.

VINING, E.P. et al. Why would you remove half a brain? The outcome of 58 children after hemispherectomy-the Johns Hopkins experience: 1968 to 1996. Pediatrics, v. 100, p. 163171, 1997.

WIEBE, S. et al. A randomized, controlled trial of surgery for temporal-lobe epilepsy. New England Journal of medicine, v. 345, n. 5, p. 311-318, 2001.

WIESER, H.G. et al. Long-term seizure outcomes following amygdalectomy. Journal of Neurosurgery, v. 98, p.751-763, 2003.

WILSON, P.J. Cerebral hemispherectomy for infantile hemiplegia. A report of 50 cases. Brain, v. 93, p. 147-180, 1970a.

WILSON, P.J. More "second thoughts" on hemispherectomy in infantile hemiplegia. Developmental Medicine and Child Neurology, v. 12, p. 799-800, 1970 b.

WYLLIE, E. Surgery for catastrophic localization-related epilepsy in infants. Epilepsia, v. 37, p. S22-25, 1996.

WYLLIE, E. et al. Epilepsy surgery in infants. Epilepsia, v. 37, p. 625-637, 1996.

WYLLIE, E. Surgical treatment of epilepsy in children. Pediatric Neurology, v.19, p. 179$188,1998$.

WYLLIE, E. et al. Seizure outcome after epilepsy surgery in children and adolescents. Annals of Neurology, v. 44, p. 740-748, 1998. 


\section{ANEXO A}

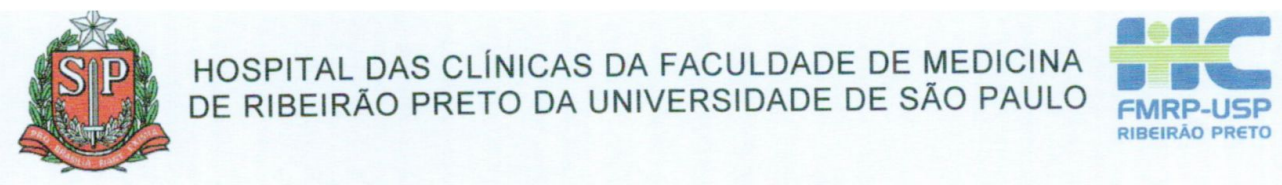

Ofício $n^{\circ} 3791 / 2017$

CEP/MGV

Ribeirão Preto, 15 de dezembro de 2017.

\section{Processo HCRP $\mathrm{n}^{\circ} 14607 / 2017$}

Prezadas Pesquisadoras,

O trabalho intitulado "MANEJO DE FÁRMACOS ANTIEPILEPTICOS APÓS HEMISFEROTOMIA: ASPECTOS PRÁTICOS, IMPLICAÇÕES EM RECORRÊNCIA DE CRISES E EM ASPECTOS NEUROPSICOLÓGICOS", foi analisado "AD REFERENDUM" pelo Comitê de Ética em Pesquisa e enquadrado na categoria: APROVADO, bem como a solicitação de dispensa de aplicação do Termo de Consentimento Livre e Esclarecido.

De acordo com Carta Circular $n^{\circ}$ 003/2011/CONEP/CNS, datada de 21/03/2011, o sujeito de pesquisa ou seu representante, quando for o caso, deverá rubricar todas as folhas do Termo de Consentimento Livre e Esclarecido - TCLE - apondo sua assinatura na última do referido Termo; o pesquisador responsável deverá da mesma forma, rubricar todas as folhas do Termo de Consentimento Livre e Esclarecido - TCLE - apondo sua assinatura na última página do referido Termo.

Este Comitê segue integralmente a Conferência Internacional de Harmonização de Boas Práticas Clínicas (IGH-GCP), bem como a Resolução $n^{\circ}$ 466/2012 CNS/MS.

Lembramos que devem ser apresentados a este CEP, o Relatório Parcial e o Relatório Final da pesquisa.

Atenciosamente,

Ilustríssimas Senhoras

LARISSA APARECIDA BATISTA

Profa Dra ana Paula Andrade hamad (Orientadora)

Depto. de Neurociências e Ciências do Comportamento

HOSPITAL DAS CLINICAS DA FACULDADE DE MEDICINA DE RIBEIRÃO PRETO DA UNIVERSIDADE DE SÃO PAULO Campus Universitário - Monte Alegre Comitê de Ética em Pesquisa do HCRP e FMRP-USP Campus Universitário - Monte Alegre
$14048-900 \quad$ Ribeirão Preto SP FWA-00002733; IRB-00002186 e Registro PB/CONEP n 5440 www.hcrp.usp.br 